\title{
Solvolysis of organophosphorus pesticide parathion with simple and $\alpha$ nucleophiles: a theoretical study
}

\author{
CHANDAN SAHU and ABHIJIT K DAS* \\ Department of Spectroscopy, Indian Association for the Cultivation of Science, Jadavpur, Kolkata, \\ West Bengal 700 032, India \\ E-mail: spakd@iacs.res.in
}

MS received 10 April 2017; revised 2 June 2017; accepted 4 June 2017

\begin{abstract}
Density functional theory (DFT) has been used to study the solvolysis process of the organophosphorus compound, O,O-diethyl $p$-nitrophenyl thiophosphate (Parathion, $\mathrm{PTH}$ ) with $\alpha$-nucleophiles [hydroxylamine anion $\left(\mathrm{NH}_{2} \mathrm{O}^{-}\right)$, hydroperoxide $\left(\mathrm{HOO}^{-}\right)$and simple nucleophile methylthiolate $\left(\mathrm{CH}_{3} \mathrm{~S}^{-}\right)$in both gas and aqueous phases. Formation of a trigonal bipyramidal intermediate at the phosphorus center followed by elimination of leaving group is considered to be the major solvolyzed pathway through addition-elimination scheme. In this study, although there are two possible orientations for incoming nucleophiles with respect to the substrate, the present reaction mechanism is found to be independent of this relative orientation. The proposed addition-elimination mechanism has been first explored here. The results indicate that the $\alpha$-effect is observed in presence of solvent. Free energy barriers for $\mathrm{NH}_{2} \mathrm{O}^{-}$and $\mathrm{HOO}^{-}$are comparable and lower than that for the simple nulcleophile, $\mathrm{CH}_{3} \mathrm{~S}^{-}$. An important physical insight of this study is that there is a significant influence of the reaction medium on the nucleophilic reaction for solvolysis of PTH irrespective of the relative orientation of incoming nucleophile group.
\end{abstract}

Keywords. Parathion; $\alpha$-nucleophiles; Solvolysis; DFT; potential energy surface; pesticide; softness; Fukui function.

\section{Introduction}

Parathion (PTH), an organophosphate (OP), is widely used as a pesticide to protect crops from insects. ${ }^{1}$ OPs show significant toxicity towards mammalian organisms; $;^{2,3}$ they inhibit the activity of the enzyme acetylcholinesterase, which is involved in the transmission of nerve impulses through phosphorylation. On the other hand, increasing use of these insecticides contaminates the environment, particularly soil and ground water. Therefore, due to the high toxicity and bio-accumulation shown by these organophosphate compounds, many methods have been developed for their degradation. ${ }^{4,5}$ The methods available presently for the degradation OPs are homogeneous and heterogeneous hydrolysis, ${ }^{6}$ photolysis, ${ }^{7}$ photochemical degradation, ${ }^{8}$ biodegradation, ${ }^{9}$ the chemical treatments based on the use of nucleophiles $^{4,5,9}$ or $\alpha$-nucleophiles. ${ }^{10,11}$ However, some of these treatments may not be very efficient or are not

\footnotetext{
*For correspondence
}

environment friendly due to the formation of products that have mild or acute toxicity. ${ }^{8,12}$ Some recent investigations pointed out that $\alpha$-nucleophiles play an effective role in the degradation of the above type of toxic compounds. ${ }^{13,14}$ Several theoretical studies were also carried out for the thermal unimolecular decomposition, ${ }^{15}$ hydrolysis, ${ }^{16,17} \alpha$-nucleophilic destruction ${ }^{18,19}$ of such lethal agents and reported that $\alpha$-nucleophiles are highly effective for decomposition of toxic OP pesticides under mild condition. ${ }^{20-24}$ As $\alpha$-Nucleophiles bear non-bonding pairs of electrons at the position $\mathrm{R}$ to the nucleophilic center, their reactivity is greater than that would be expected on the basis of the pKa values. ${ }^{25}$ Moreover, the high reactivity of $\alpha$-Nucleophiles towards phosphorus makes them reagents of special interest for the destruction of nerve gases and other organophosphorus poisons. ${ }^{26}$ But the origin of $\alpha$-effect remains controversial till today. ${ }^{20,25,27-44}$ Earlier theoretical studies suggested that the origin of $\alpha$-effect includes ground-state (GS) destabilization, transition-state (TS) stabilization, thermodynamic stabilization of products

Electronic supplementary material: The online version of this article (doi:10.1007/s12039-017-1322-2) contains supplementary material, which is available to authorized users. 
and solvent effects. ${ }^{20,25,27-44}$ Interestingly, solvent effect is also contentious for the $\alpha$-effect, whether it is intrinsic properties of the nucleophiles or solvent induced phenomenon. ${ }^{25,28-31,33,35,42-50}$ The gas phase reactions between various anions and OP compounds have been investigated using mass spectrometry ${ }^{51,52}$ in absence of solvents and these findings reported that $\alpha$-nucleophiles show greater reactivity than normal nucleophiles. Biberbaum et al. ${ }^{28}$ in their study of gas phase reaction between $\alpha$-nucleophiles and alkyl chlorides using a tandem flowing afterglow-selected ion flow tube instrument concluded that the $\alpha$-effect is not due to an intrinsic property of the anion, instead, it is due to the solvent effect. But this is in contradiction to other experimental and theoretical studies of McAnoy et al., ${ }^{29,53}$ with gas phase $\alpha$-effect. In an experimental study, DePuy et $a l .{ }^{28}$ reported that nucleophilicity of peroxide anion is similar to hydroxide in gas phase and the $\alpha$-effect is not significant in the absence of solvent. These results motivated us to investigate solvent effects on $\alpha$-nucleophiles as well as on simple nucleophiles (no $\alpha$-effect). However, depending primarily on the alkylation or arylation state of OPs and the nature of nucleophile, different pathways ${ }^{19}$ of degradation were reported. It has been reported that the attack at the phosphorus center, $\mathrm{SN} 2(\mathrm{P})$ is the sole reaction pathway ${ }^{54}$ for the reactions of Paraxon and its sulfur analogue, Parathion. Another study of alkaline perhydrolysis of a model VX compound reported that all the hydrolysis reactions proceed through the phosphoruscentered pentavalent intermediate. ${ }^{29,55}$ There are two different types of $\alpha$-nucleophiles and one simple nucleophile used for nucleophilic destruction. Among various $\alpha$-nucleophiles, the (-N-O- type) $\alpha$-nucleophiles, i.e., hydroxybenzotriozoles have been used recently for the solvolysis of organophosphate esters, which show faster rate of solvolysis for such toxic esters. ${ }^{56}$ This finding motivated us to explore the solvolysis of PTH with $\mathrm{NH}_{2} \mathrm{O}^{-}$nucleophiles. Previous theoretical study ${ }^{57}$ of solvolysis of VX using hydroxide and $\alpha$-nucleophile hydroperoxide inferred that hydroperoxide is a better nucleophile compared to hydroxide as hydroperoxide solely produces non-toxic products. Therefore, we have taken $\mathrm{HOO}^{-}$as a $\alpha$-nuclophile for detoxification. Other type of simple nucleophiles, namely $\mathrm{CH}_{3} \mathrm{~S}^{-}$ and $\mathrm{CH}_{3} \mathrm{O}^{-}$were reported ${ }^{58}$ theoretically for solvolysis of different type of phosphate triesters. Xia et al. ${ }^{59}$ reported a detail theoretical study of the methanolysis of paraoxon and analogous reactions with sulfur substituted at the key oxygen position. However, no theoretical work is available so far in the literature for the thiolysis of PTH by $\mathrm{CH}_{3} \mathrm{~S}^{-}$. Earlier theoretical study ${ }^{60}$ reported that there is a significant attack at the phosphorus center of phosphate triesters having an aryl-derived leaving group by $\mathrm{CH}_{3} \mathrm{~S}^{-}$nucleophile in gas phase.

In order to investigate the $\alpha$-effect of the nucleophiles, we have performed a systematic computational study of the solvolysis reaction of PTH with $\alpha$-nucleophiles $\left(\mathrm{NH}_{2} \mathrm{O}^{-}, \mathrm{HOO}^{-}\right)$and simple nucleophile, $\mathrm{CH}_{3} \mathrm{~S}^{-}$in both gas and aqueous phases. As the biological activity of molecules depends on the electronic structure of the active part of a compound and its conformation, we first performed a conformational analysis of PTH. As the nucleophilic attack at the phosphorous center $\left(\mathrm{SN}_{2} @ \mathrm{P}\right)$ is the important pathway for solvolysis of OP pesticides, ${ }^{19,29,54,55}$ a detailed study of these pathways has been discussed for these three nucleophiles for the solvolysis of PTH. In addition, a comprehensive analysis has been performed to know the reactivity of the three nucleophiles, $\mathrm{NH}_{2} \mathrm{O}^{-}, \mathrm{HOO}^{-}$and $\mathrm{CH}_{3} \mathrm{~S}^{-}$in the $\mathrm{SN}_{2} @ \mathrm{P}$ reaction using conceptual density functional theory.

\section{Computational details}

To find out stable conformers of PTH, a molecular dynamics (MD) conformational search has been performed with an unconstrained MD trajectory using the Verlet velocity algorithm and NVE thermostat along with other default parameters in Gabedit V.2.3.8. ${ }^{61}$ The PM6 semi-empirical method, as implemented in MOPAC $2009,{ }^{62}$ has been used to find the minimum conformational geometries. Twenty five representative minimum structures, which are selected from the rigorous conformational search for final validation of the conformational analysis, are studied by the density functional theory (DFT). The DFT, with the hybrid functional (M06-2X) of Truhlar and Zhao, ${ }^{63}$ has been employed to fully optimize the geometries of all the molecular species involved in this study. The standard $6-31++\mathrm{G}(\mathrm{d}, \mathrm{p})^{64}$ basis set is used for all the atoms. The theoretical level for this combination of method and basis set is denoted as M062X/6$31++\mathrm{G}(\mathrm{d}, \mathrm{p})$. The normal-mode analyses have been performed at the same level of theory for reactants and products as well as TS geometries, and the minima are characterized with no imaginary frequency, whereas the presence of one imaginary frequency is the characteristic of TS. To evaluate the zeropoint vibration energy (ZPVE) and thermal corrections to the Gibbs free energy at $\mathrm{T}=298.15 \mathrm{~K}$, harmonic vibrational frequencies are calculated at the M062X/6-31++G(d,p) level. The first-order saddle points, which are the transition states that connect the equilibrium geometries, are obtained using the synchronous transit-guided quasi-Newton (STQN) method. A parallel intrinsic reaction coordinate (IRC) calculation with all transition states has been performed to confirm whether these transition states connect the right minima or not. ${ }^{65,66}$ Single-point energy calculation are performed on the M062X/6-31++G(d,p) optimized geometries at MP2/6$311++\mathrm{G}(2 \mathrm{~d}, 2 \mathrm{p})$ level. ${ }^{67-72}$ Unless stated otherwise, energy 
values reported herein include zero-point vibrational energy. The aqueous-phase calculations have been performed at the same level of theory similar to the gas-phase ones. The solvent effect has been taken into account by the conductor-like screening solvation model (COSMO), ${ }^{73}$ as implemented in Gaussian 09. ${ }^{74}$ All COSMO calculations in this study have been performed by using default choice of the Gaussian 09 program with the recommended standard parameters. In our previous study ${ }^{19}$ of nucleophilic degradation of fenitrothion by anionic nucleophiles, it has been reported that the COSMO model provides more appropriate information on energetics than the integral equation formalism polarized continuum solvation model (IEF-PCM) ${ }^{75-79}$ when compared with the experimental findings. Therefore, we have used the aqueous-phase energetics as well as geometric parameters of the COSMO model in successive discussions. All electronic structure calculations have been performed using the Gaussian 09 suite of quantum chemistry programs. ${ }^{74}$

The reactivity descriptor, which is used in this work, is related to the local softness, s(r), the global softness, $S$ of the system ${ }^{80}$ and the Fukui function, ${ }^{81} \mathrm{f}(\mathrm{r})$ by the following relation:

$s(r)=f(r) S$

Using the finite difference approximation, as proposed by Yang and Mortier, ${ }^{82}$ the compact form of Fukui functions of an atom $\mathrm{k}$ in a molecule with $\mathrm{N}$ electrons are,

$f_{k}^{+}=\left[q_{k}(N+1)-q_{k}(N)\right]$ for nucleophilic attack

$f_{k}^{-}=\left[q_{k}(N)-q_{k}(N-1)\right]$ for electrophilic attack

where $q_{k}(N), q_{k}(N-1), q_{k}(N+1)$, are the electron population for the atom $\mathrm{k}$ in the neutral, cationic, anionic states of a system, respectively. The electron populations are evaluated at the neutral molecular geometry in both gas and aqueous phases. The Mulliken ${ }^{83}$ charges calculated using the optimized geometries at M062X/6-31++G(d,p) level is utilized to compute $f_{k}$. The finite difference formula is used to calculate the global softness $(\mathrm{S})$, i.e.,

$S=1 /(\mathrm{IE}-\mathrm{EA})$

where, IE and EA are the first vertical ionization energy and electron affinity, respectively. IE and EA can be estimated from the Koopman's theorem ${ }^{84}$ as the energy of the highest occupied molecular orbital (HOMO) and the lowest unoccupied molecular orbital (LUMO), respectively. Thus, $\mathrm{S}$ can be calculated from the following the expression,

$S=1 /\left(E_{\text {LUMO }}-E_{\text {HOMO }}\right)$

The local softness of nucleophile and electrophile can be defined as,

$s_{k}^{-}=S f_{k}^{-}$

$s_{k}^{+}=S f_{k}^{+}$

In our study, $\mathrm{s}^{+}$represents the local softness of the $\mathrm{P}$ atom in PTH and $\mathrm{s}^{-}$represents the local softness of the O/S atom in nucleophiles. From the local version of the well-known hard soft acid base (HSAB) principle of Gazquez ${ }^{85}$ and Nguyen et al., ${ }^{86}$ and after a generalization by Ponti, ${ }^{87}$ it emerges that the interaction between reaction partners is favored when it occurs through minimal $\Delta \mathrm{s}(\mathrm{r})$, where,

$\Delta \mathrm{s}(\mathrm{r})=\left|\mathrm{s}^{+}(r)-\mathrm{s}^{-}(r)\right|$

\section{Results and Discussion}

\subsection{Conformational search of PTH}

Low-energy conformations of molecular systems are found through conformational search by varying geometric parameters. Among the 25 selected conformers of PTH, the minima are finally optimized at M062X/6$31++\mathrm{G}(\mathrm{d}, \mathrm{p})$ level of theory. After DFT optimization, we get five lower-energy structures. The optimized geometries are shown in Figure 1, with the relative energies given in the parentheses. The lowest energy conformer found here is M1. The most stable ground state structures obtained by us are in good agreement with that reported previously by Ford-Green et al., ${ }^{88}$ who carried out the conformational search for PTH using DFT.

\subsection{Reaction mechanisms: solvolysis of PTH}

The nucleophilic substitution reactions for solvolysis of phosphotriesters compounds illustrate that substitution reactions mainly occur at phosphorus center through associative pathway. ${ }^{89,90}$ There are two possibilities in associative pathway: one is addition-elimination mechanism and other is direct displacement pathway. According to earlier results, ${ }^{16,17,55,91,92}$ the multistep pathway occurs in sarin, acephate, O,S-dimethyl methylphosphonothiolate (VX type model compound) and tabun, but paraoxon, parathion, fenitrothion and demeton-S appear to be hydrolyzed through direct displacement pathway. In contrast to these results, we have obtained only the multistep pathway for our systems, although several attempts have been made to find out the single step pathway. Previous theoretical work ${ }^{16}$ based on direct displacement type mechanisms was reported for the hydrolysis of a number of phosphotriesterase (PTE) substrates, but the solvolysis of parathion based on addition-elimination type mechanisms by $\alpha$-nuclophiles has not yet been investigated theoretically. In the present investigation, the solvolysis of PTH is mainly due to the addition-elimination mechanism, involving the formation of trigonal bipyramidal intermediate and its further decomposition. The schematic representation of the aforesaid mechanism is as follows (Scheme 1).

Nucleophilic attack on the P atom of PTH followed by the release of p-nitrophenol through the SN2-type reaction is consistent with the addition-elimination 

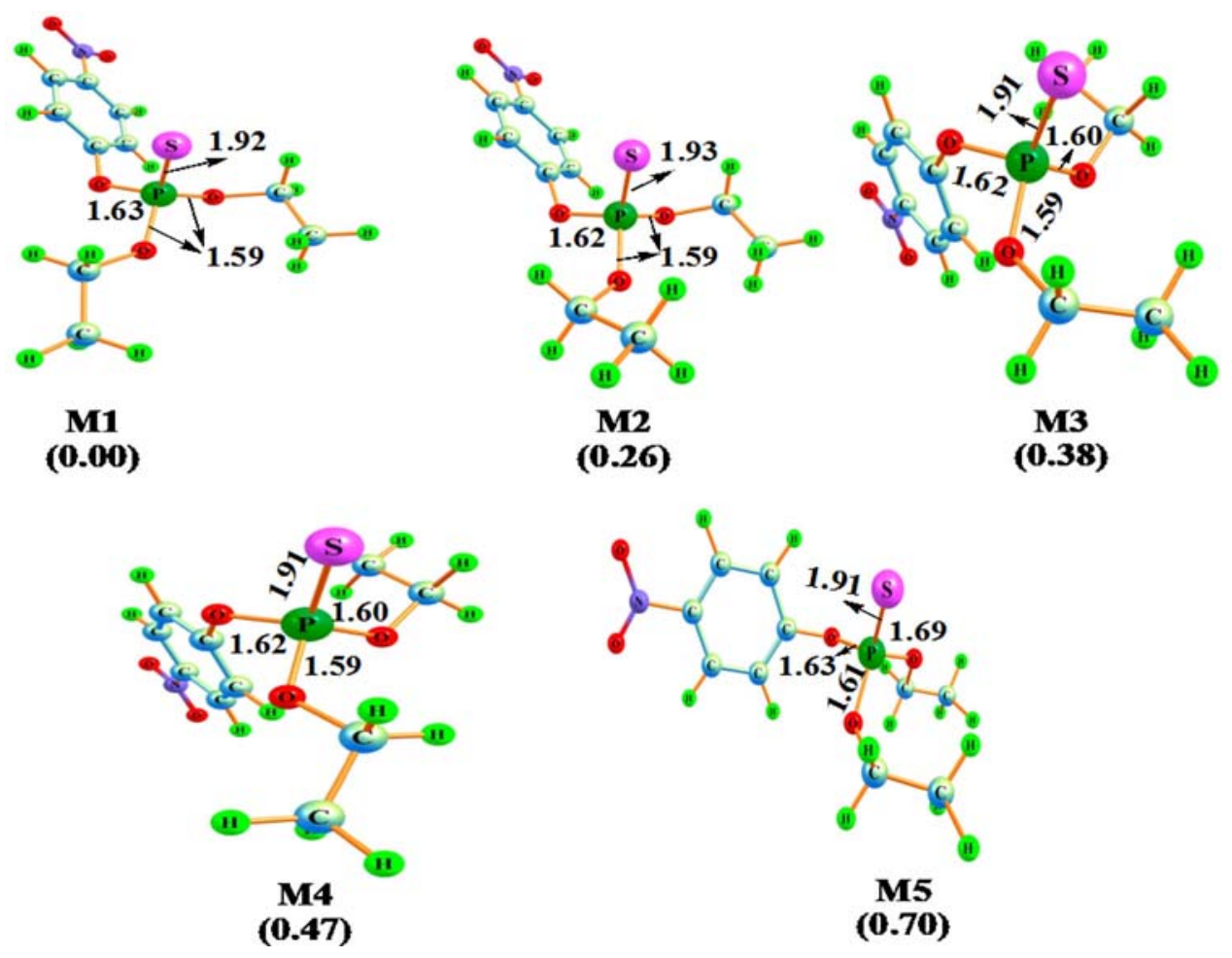

Figure 1. Gas-phase-optimized geometries at M062X/6-31++G(d,p) level [(Relative energies in $\mathrm{kcal} \mathrm{mol}^{-1}$ are given the parenthesis)] for the most stable conformers of PTH with important geometrical parameters.

mechanism. Depending on the relative orientation of incoming nucleophilic group, there are two possible pathways. In the first pathway, proton of hydroxylamine and hydroperoxide and methyl group of $\mathrm{CH}_{3} \mathrm{~S}^{-}$are in the opposite direction to the phosphoryl sulfur atom $(\mathrm{C} 1$ path), whereas in second pathway, it is positioned in the same way (C2 path). All possible pathways have been explored in both gas and aqueous phases. Interestingly, second pathway is not established for gas phase. To confirm this finding, we have scanned the potential energy surface (PES) (given in the Supplementary Information [SI]) in the gas phase for the P-Nu bond formation and it is observed that there is a steady increase in energy, having no local minimum or maximum that might suggest absence of any transition state. However, we have bestowed light on only one pathway where orientation of nucleophile is opposite to phosphoryl sulfur atom in the gas phase and established both pathways in the aqueous phase. To facilitate the identification of each stationary point, we adopt a nomenclature to characterize them in the following sections. In Figures 2 to 7 , $\mathrm{a}, \mathrm{b}, \mathrm{c}$ in the entire species name indicate the nucleophiles $\mathrm{NH}_{2} \mathrm{O}^{-}, \mathrm{HOO}^{-}, \mathrm{CH}_{3} \mathrm{~S}^{-}$, respectively, and there are two pathways associated with two relative orientations in aqueous phase, one is named as $\mathrm{Cl}_{\mathrm{aq}}$ and other is $\mathrm{C} 2_{\mathrm{aq}}$. The relative energies calculated at MP2/6$311++\mathrm{G}(2 \mathrm{~d}, 2 \mathrm{p}) / / \mathrm{M} 062 \mathrm{X} / 6-31++\mathrm{G}(\mathrm{d}, \mathrm{p})$ level, relative free energies and enthalpies calculated at M062X/6$31++\mathrm{G}(\mathrm{d}, \mathrm{p})$ level are given in Table 1 .

\subsection{Reaction of PTH with hydroxylamine anion $\left(\mathrm{NH}_{2} \mathrm{O}^{-}\right)$}

First we have studied solvolysis mechanism of PTH with $\mathrm{NH}_{2} \mathrm{O}^{-}$in both gas and aqueous phases. The optimized structures are given in Figure 2 and the free energy profiles obtained from M062X/6-31++G(d,p) calculation are presented in Figure 3. All the coordinates associated with the stationary points and $\Delta \mathrm{E}$ values calculated at M062X/6-31++G(d,p) are given in the SI.

In the first step of gas phase solvolysis, a reaction complex (RCa) is formed, having $38.0 \mathrm{kcal} \mathrm{mol}^{-1}$ lower in free energy than the infinitely separated complex $\left(\mathrm{PTH}+\mathrm{NH}_{2} \mathrm{O}^{-}\right)$. Here, orientation of nucleophile is opposite to the phosphoryl sulfur atom. The $\mathrm{RCa}$ is stabilized through the formation of a hydrogen bond between the $\mathrm{O}$ atom of the nucleophile and $\mathrm{H}$ atom of both $-\mathrm{OC}_{2} \mathrm{H}_{5}$ moiety with distances of 1.93 and $1.94 \AA$. Free energy profile (Figure 3) shows that nucleophile attacks at the $\mathrm{P}$ center of PTH to form an intermediate, IMa, through a unique trigonal bipyramidal (TBP) transition state, TS1a, having activation energy $(\Delta \mathrm{E})$ of $6.9 \mathrm{kcal} \mathrm{mol}^{-1}$ and activation free energy $(\Delta \mathrm{G})$ of $6.8 \mathrm{kcal} \mathrm{mol}^{-1}$. Our calculated values of both $\Delta \mathrm{E}$ 


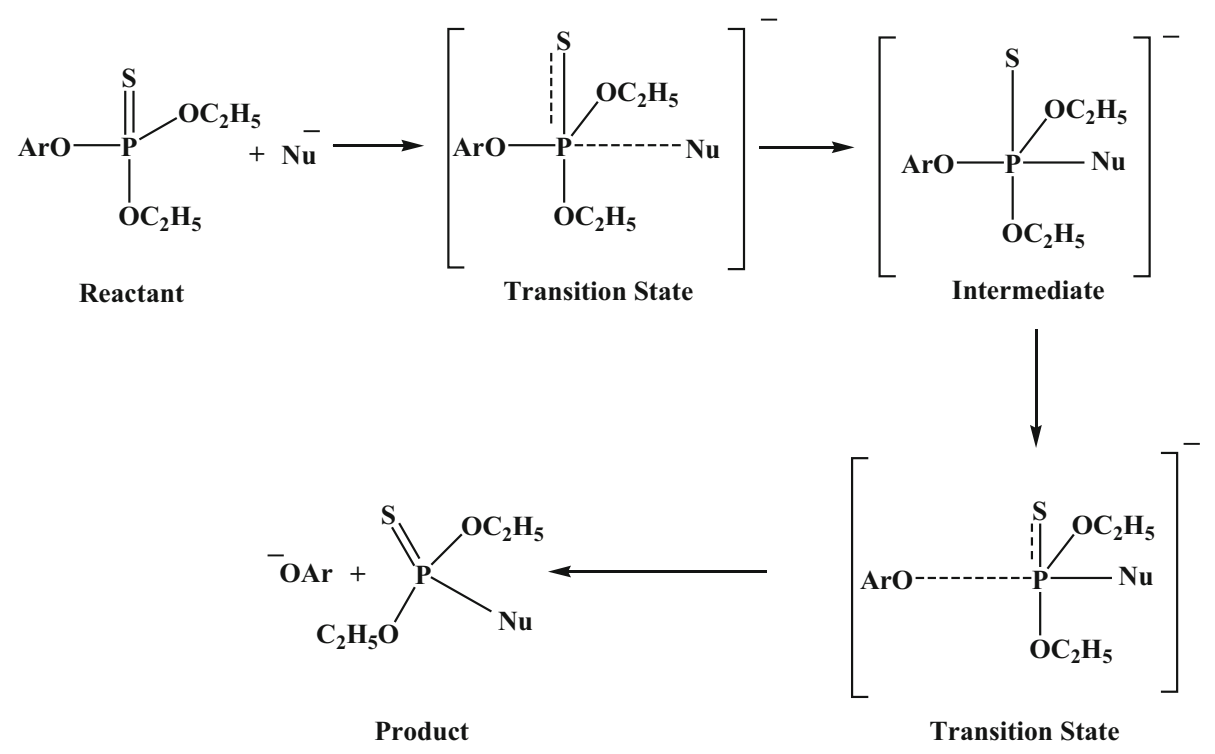

Scheme 1. Addition-elimination reaction mechanism for the nucleophilic solvolysis of PTH. reaction of solvolysis of PTH.

and $\Delta \mathrm{G}$ are comparable with that reported ${ }^{92}$ for the alkaline hydrolysis of paraoxon $(\Delta \mathrm{E}=8.7, \Delta \mathrm{G}=$ $\left.8.6 \mathrm{kcal} \mathrm{mol}^{-1}\right)$, methyl parathion $(\Delta \mathrm{E}=8.7, \Delta \mathrm{G}=$ $\left.8.8 \mathrm{kcal} \mathrm{mol}^{-1}\right)$ and fenitrothion $(\Delta \mathrm{E}=9.0, \Delta \mathrm{G}=$ $\left.9.3 \mathrm{kcal} \mathrm{mol}^{-1}\right)$ at MP2/6-311++G(2d,2p) // B3LYP/6$31+\mathrm{G}(\mathrm{d})$ level of theory. In the next step, -OAr group is eliminated from IMa, which is a penta-coordinated intermediate with a unique trigonal bipyramidal structure, to form the product, $\mathrm{Pa}$, situated $73.9 \mathrm{kcal} \mathrm{mol}^{-1}$ below in free energy profile, via the transition state, TS2a, having activation free energy of $0.7 \mathrm{kcal} \mathrm{mol}^{-1}$. The vibrational mode of the single imaginary frequency of TS2a corresponds to the complete rupture of the $\mathrm{P}-\mathrm{O}$ bond. This value is also comparable to the earlier reported results ${ }^{92}$ for alkaline hydrolysis of paraoxon, methyl parathion, fenitrothion. The reason for this lower energy barrier is due to utmost similarity in structure between IMa and TS2a and it is consistent with the previous studies of paraoxon hydrolysis. ${ }^{92}$ In addition, from the enthalpy values, it is observed that formation of $\mathrm{Pa}$ is also exothermic in nature.

Figure 3 represents the PES of the reaction mechanisms of PTH with $\mathrm{NH}_{2} \mathrm{O}^{-}$at M062X/6-31++G(d,p) level in the aqueous phase. Here, two alternative pathways are discussed. Both pathways are started from the same substrate but orientation of incoming nucleophile is different. Figure 2 shows a significant structural difference between $\mathrm{RCa}-\mathrm{C} 1 \mathrm{aq}$ and $\mathrm{RCa}-\mathrm{C} 2 \mathrm{aq}$ complexes. But nucleophilic attack occurs in both the stationary points via TS1a-C1aq and TS1a-C2aq to form an intermediate IMa-C1aq and IMa-C2aq, respectively. The $\Delta \mathrm{E}$ and
$\Delta G$ values for both TS are almost similar but lower than the gas phase values. This is probably due to more $\alpha$-effect of the nucleophile in the solvent. In both pathways for two relative orientations, the product formation is exergoinc in nature $(\Delta \mathrm{G}$ of $\mathrm{Pa}-\mathrm{Cl} \mathrm{aq}=-23.3$ and $\Delta \mathrm{G}$ of Pa-C2aq $=-22.9 \mathrm{kcal} \mathrm{mol}^{-1}$ ). The normal-mode analysis and the IRC calculation confirmed that both transition states are well connected by the intermediate and product. The aforementioned reaction mechanisms are in good agreement with the addition-elimination mechanism in spite of different orientation of incoming nucleophilic group. As the activation energy barrier for elimination of leaving group is lower compared to addition of nucleophile group, the formation of TBP intermediate is the rate-limiting step and this outcome agrees well with the previous results. ${ }^{92}$

\subsection{Reaction of PTH with hydroperoxide anion $\left(\mathrm{HOO}^{-}\right)$}

Hydroperoxide anion is also an efficient $\alpha$-nucleophile for solvolysis of PTH and it follows the similar type mechanism as described above for $\mathrm{NH}_{2} \mathrm{O}^{-}$. The optimized stationary points and free energy profile for both phases are presented in Figure 4 and Figure 5, respectively. Figure 5 shows reactant complex (RCb), which is located $36.9 \mathrm{kcal} \mathrm{mol}^{-1}$ below the reactants $\left(\mathrm{PTH}+\mathrm{HOO}^{-}\right)$, transforms further into intermediate, $\mathrm{IMb}$, via a TBP geometric transition state, TS1b, having activation energy $(\Delta \mathrm{E})$ of $7.6 \mathrm{kcal} \mathrm{mol}^{-1}$ and activation free energy $(\Delta \mathrm{G})$ of $7.4 \mathrm{kcal} \mathrm{mol}^{-1}$. These values are 
Table 1. Relative energies $(\Delta \mathrm{E})$ calculated at MP2/6-311++G(2d,2p) // M062X/6$31++\mathrm{G}(\mathrm{d}, \mathrm{p})$ level of theory and $\Delta \mathrm{H}$ and $\Delta \mathrm{G}$ calculated at M062X/6-31++G(d,p) level for all the species involved in the reactions.

\begin{tabular}{|c|c|c|c|c|c|c|c|}
\hline \multicolumn{4}{|c|}{ Gas } & \multicolumn{4}{|c|}{ Aqueous } \\
\hline Species & $\Delta \mathrm{E}$ & $\Delta \mathrm{H}$ & $\Delta \mathrm{G}$ & Species & $\Delta \mathrm{E}$ & $\Delta \mathrm{H}$ & $\Delta \mathrm{G}$ \\
\hline $\mathrm{PTH}+\mathrm{NH}_{2} \mathrm{O}^{-}$ & 0.0 & 0.0 & 0.0 & $\mathrm{PTH}_{\mathrm{aq}}+\mathrm{NH}_{2} \mathrm{O}^{-} \mathrm{aq}$ & 0.0 & 0.0 & 0.0 \\
\hline $\mathrm{RCa}$ & -37.6 & -49.6 & -38.0 & $\mathrm{RCa}-\mathrm{C} 1_{\mathrm{aq}}$ & -2.8 & -1.5 & 8.1 \\
\hline TS1a & -30.7 & -45.8 & -31.2 & $\mathrm{TS} 1 \mathrm{a}-\mathrm{C} 1_{\mathrm{aq}}$ & 1.9 & 0.2 & 11.7 \\
\hline IMa & -55.1 & -72.8 & -58.7 & $\mathrm{IMa}-\mathrm{C} 1_{\mathrm{aq}}$ & -16.7 & -22.7 & -9.1 \\
\hline TS2a & -55.3 & -71.7 & -58.0 & $\mathrm{TS} 2 \mathrm{a}-\mathrm{C} 1_{\mathrm{aq}}$ & -17.0 & -22.8 & -8.4 \\
\hline \multirow[t]{2}{*}{$\mathrm{Pa}$} & -71.5 & -86.3 & -73.9 & $\mathrm{~Pa}-\mathrm{C} 1_{\mathrm{aq}}$ & -31.8 & -34.2 & -23.3 \\
\hline & & & & $\mathrm{RCa}-\mathrm{C} 2_{\mathrm{aq}}$ & -2.5 & -1.1 & 8.6 \\
\hline $\mathrm{PTH}+\mathrm{HOO}^{-}$ & 0.0 & 0.0 & 0.0 & TS1a-C2 $2_{\mathrm{aq}}$ & 2.2 & 0.3 & 13.3 \\
\hline $\mathrm{RCb}$ & -36.3 & -49.1 & -36.9 & $\mathrm{IMa}-\mathrm{C} 22_{\mathrm{aq}}$ & -17.4 & -23.4 & -8.4 \\
\hline TS1b & -28.7 & -43.4 & -29.5 & $\mathrm{TS} 2 \mathrm{a}-\mathrm{C} 22_{\mathrm{aq}}$ & -17.6 & -23.5 & -8.2 \\
\hline $\mathrm{IMb}$ & -53.2 & -70.5 & -55.9 & $\mathrm{~Pa}-\mathrm{C} 2_{\mathrm{aq}}$ & -32.0 & -34.6 & -22.9 \\
\hline $\mathrm{TS} 2 \mathrm{~b}$ & -52.1 & -67.5 & -54.3 & $\mathrm{PTH}_{\mathrm{aq}}+\mathrm{HOO}_{\mathrm{aq}}^{-}$ & 0.0 & 0.0 & 0.0 \\
\hline \multirow[t]{2}{*}{$\mathrm{Pb}$} & -59.1 & -73.7 & -61.6 & $\mathrm{RCb}-\mathrm{C} 1_{\mathrm{aq}}$ & -3.8 & -2.3 & 7.9 \\
\hline & & & & $\mathrm{TS} 1 \mathrm{~b}-\mathrm{C} 1_{\mathrm{aq}}$ & 1.3 & -0.3 & 11.5 \\
\hline $\mathrm{PTH}+\mathrm{CH}_{3} \mathrm{~S}^{-}$ & 0.0 & 0.0 & 0.0 & $\mathrm{IMb}-\mathrm{C} 1_{\mathrm{aq}}$ & -11.3 & -16.5 & -2.2 \\
\hline $\mathrm{RCc}$ & -25.4 & -34.6 & -23.6 & $\mathrm{TS} 2 \mathrm{~b}-\mathrm{C} 1_{\mathrm{aq}}$ & -10.8 & -15.2 & -1.4 \\
\hline TS1c & -18.9 & -29.8 & -16.6 & $\mathrm{~Pb}-\mathrm{C} 1_{\mathrm{aq}}$ & -24.1 & -25.1 & -13.8 \\
\hline IMc & -26.2 & -35.9 & -24.0 & $\mathrm{RCb}-\mathrm{C} 2_{\mathrm{aq}}$ & -3.3 & -1.8 & 8.1 \\
\hline $\mathrm{TS} 2 \mathrm{c}$ & -26.3 & -35.9 & -23.3 & $\mathrm{TS} 1 \mathrm{~b}-\mathrm{C} 2 \mathrm{aq}$ & 1.0 & -0.9 & 12.2 \\
\hline \multirow[t]{14}{*}{$\mathrm{Pc}$} & -41.4 & -49.3 & -39.0 & $\mathrm{IMb}-\mathrm{C} 2_{\mathrm{aq}}$ & -14.3 & -19.1 & -4.4 \\
\hline & & & & $\mathrm{TS} 2 \mathrm{~b}-\mathrm{C} 22_{\mathrm{aq}}$ & -11.6 & -16.0 & -1.3 \\
\hline & & & & $\mathrm{Pb}-\mathrm{C} 2_{\mathrm{aq}}$ & -21.1 & -23.4 & -11.6 \\
\hline & & & & $\mathrm{PTH}_{\mathrm{aq}}+\mathrm{CH}_{3} \mathrm{~S}_{\mathrm{aq}}^{-}$ & 0.0 & 0.0 & 0.0 \\
\hline & & & & $\mathrm{RCc}-\mathrm{C} 1_{\mathrm{aq}}$ & -4.4 & -1.5 & 6.7 \\
\hline & & & & $\mathrm{TS} 1 \mathrm{c}-\mathrm{C} 1_{\mathrm{aq}}$ & 6.8 & 7.1 & 18.7 \\
\hline & & & & $\mathrm{IMc}-\mathrm{C} 1_{\mathrm{aq}}$ & 1.8 & 3.6 & 15.2 \\
\hline & & & & $\mathrm{TS} 2 \mathrm{c}-\mathrm{C} 1_{\mathrm{aq}}$ & 3.5 & 4.6 & 17.1 \\
\hline & & & & $\mathrm{Pc}-\mathrm{C} 1_{\mathrm{aq}}$ & -15.2 & -11.6 & -1.9 \\
\hline & & & & $\mathrm{RCc}-\mathrm{C} 2_{\mathrm{aq}}$ & -3.4 & -1.3 & 9.4 \\
\hline & & & & TS1c-C2 $2_{\mathrm{aq}}$ & 8.1 & 8.0 & 20.2 \\
\hline & & & & $\mathrm{IMc}-\mathrm{C} 2_{\mathrm{aq}}$ & 2.6 & 4.5 & 17.5 \\
\hline & & & & $\mathrm{TS} 2 \mathrm{c}-\mathrm{C} 22_{\mathrm{aq}}$ & 3.0 & 4.6 & 18.3 \\
\hline & & & & $\mathrm{Pc}-\mathrm{C} 2_{\mathrm{aq}}$ & -12.3 & -9.2 & -0.5 \\
\hline
\end{tabular}

All energies are in $\mathrm{kcal} \mathrm{mol}^{-1}$.

comparable with previously reported results ${ }^{92}$ of alkaline hydrolysis of organophosphorus pesticides. In the next step, a bond cleavage is occurred in the TS, TS2b, (activation free energy $(\Delta \mathrm{G}), 1.6 \mathrm{kcal} \mathrm{mol}^{-1}$ ) to form the product, $\mathrm{Pb}$. IRC calculation for the corresponding TS confirms the formation of final product via complete breaking of the P-O bond.

In case of aqueous phase, two possible pathways are explored. Both the reactant complexes, $\mathrm{RCb}-\mathrm{C} 1_{\mathrm{aq}}$ and $\mathrm{RCb}-\mathrm{C} 2_{\mathrm{aq}}$ are lower in free energy in the energy profile, and nucleophilic attack occurs irrespective of orientations of the PTH and forms unique trigonal bipyramidal intermediate structures through the TS1b-C1 $1_{\text {aq }}(\Delta \mathrm{G}=$ $\left.3.6 \mathrm{kcal} \mathrm{mol}^{-1}\right)$ and TS1b-C $2_{\mathrm{aq}}\left(\Delta \mathrm{G}=4.1 \mathrm{kcal} \mathrm{mol}^{-1}\right)$, respectively. Next in the elimination process of leaving group, -OAr is eliminated to form the product complexes, $\mathrm{Pb}-\mathrm{C} 1_{\mathrm{aq}}$ and $\mathrm{Pb}-\mathrm{C} 2_{\mathrm{aq}}$ via the transition state, $\mathrm{TS} 2 \mathrm{~b}-\mathrm{C} 1_{\mathrm{aq}}$ and TS2b-C2 $2_{\mathrm{aq}}$. The IRC calculation for both the TS corroborates with the leaving of -OAr group through the intermediate and the product complex. Here, formation of the intermediate is rate-determining step and $\Delta \mathrm{E}$ values for corresponding TS is lower in aqueous phase compared to gas phase due to more $\alpha$-effect in solvent.

\subsection{Reaction of PTH with methanethiolate anion $\left(\mathrm{CH}_{3} \mathrm{~S}^{-}\right)$}

In contrast to the above-mentioned $\alpha$-nucleophiles, $\mathrm{CH}_{3} \mathrm{~S}^{-}$is also an efficient simple nucleophile for the 

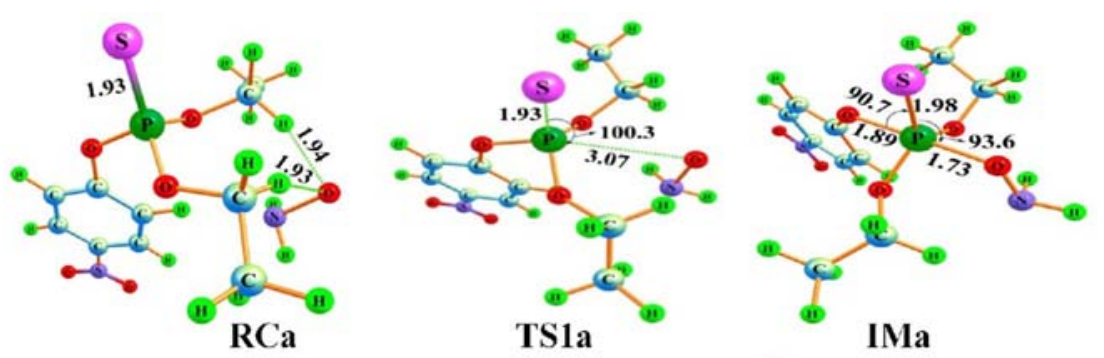

IMa
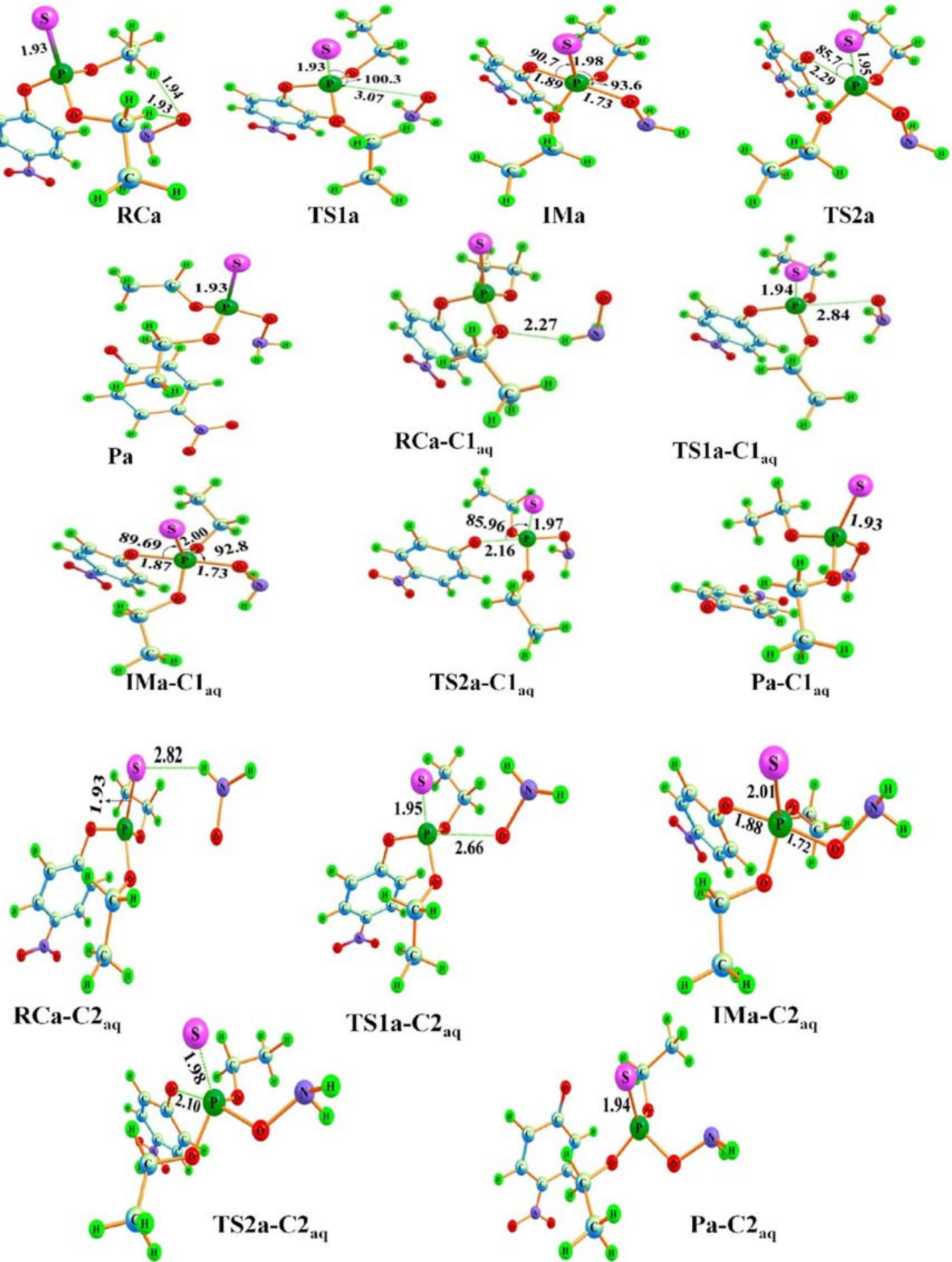

TS1a-C2 aq

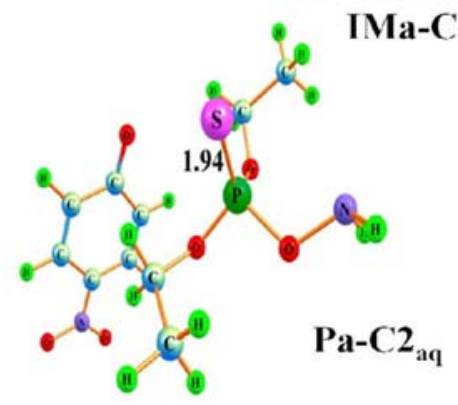

Figure 2. Optimized geometries with important parameters in the gas and aqueous phases obtained at M062X/6-31++G(d,p) level for all the species involved in the reaction of parathion with $\mathrm{NH}_{2} \mathrm{O}^{-}$. All bond lengths and angels are in $\AA$ and $\left(^{\circ}\right.$ ), respectively.

detoxification of PTH and other organophosphate esters. The optimized geometries in gas and aqueous phases are given in Figure 6 and the potential energy profiles obtained from M062X/6-31++G(d,p) calculation are presented in Figure 7.
An adduct ( $\mathrm{RCc}$ ), with $23.6 \mathrm{kcal} \mathrm{mol}^{-1}$ lower in free energy with respect to isolated reactants, is formed during the initial nucleophilic approach towards PTH in gas phase. The RCc once formed transforms into another intermediate, IMc, through a TBP geometric 


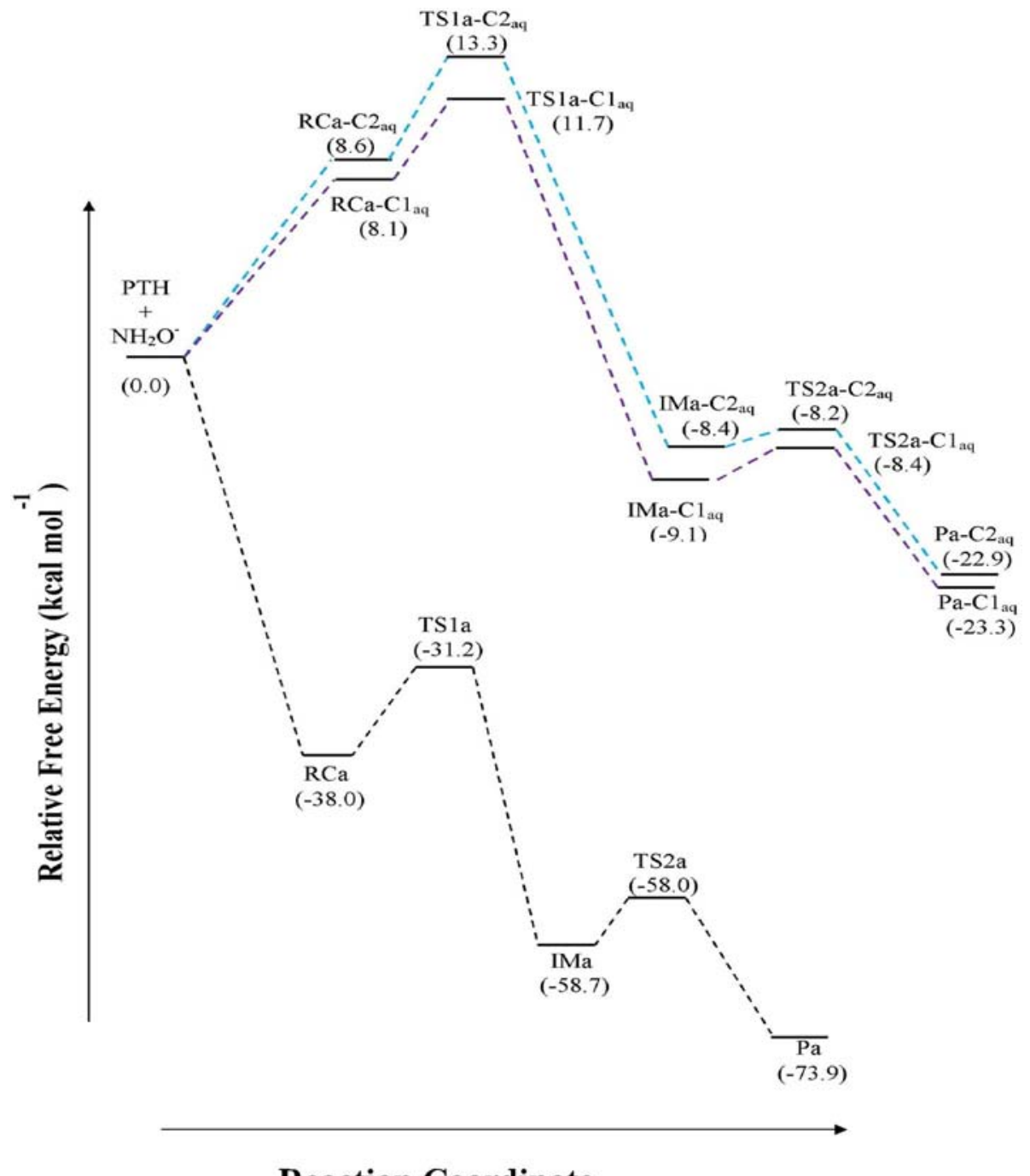

\section{Reaction Coordinate}

Figure 3. Free energy profile for the reaction of parathion with $\mathrm{NH}_{2} \mathrm{O}^{-}$at M062X/6-31++G(d,p) level of theory in gas (black color line) and aqueous (violet and cyan color lines) phases. C1 (violet line) and C2 (cyan line) correspond to the relative orientation in aqueous phase.

transition state, TS1c, having activation energy $(\Delta \mathrm{E})$ of $6.5 \mathrm{kcal} \mathrm{mol}^{-1}$ and activation free energy $(\Delta \mathrm{G}$ of $7.0 \mathrm{kcal} \mathrm{mol}^{-1}$. After surmounting the transition state, TS1c, the intermediate, IMc, a penta-coordinated intermediate with a TBP structure, is formed. In the very next step, p-nitrophenol can be eliminated from IMc to form the product, Pc, via the transition state, TS2c, having activation free energy of $0.7 \mathrm{kcal} \mathrm{mol}^{-1}$. The vibrational mode of the single imaginary frequency of TS2c corresponds to the breaking of P-O bond. The greater similarity between intermediate and transition state structures is responsible for lowering of the free energy barrier.

The aqueous phase reaction of PTH with $\mathrm{CH}_{3} \mathrm{~S}^{-}$ passes through the formation of two different rela- tive orientations of reactant complex, $\mathrm{RCc}-\mathrm{Cl}_{\mathrm{aq}}$ and $\mathrm{RCc}-\mathrm{C} 2_{\mathrm{aq}}$. But nucleophilic attack at $\mathrm{P}$ center occurs in both the stationary points via TS1c-C $1_{\text {aq }}$ and $\mathrm{TS} 1 \mathrm{c}-\mathrm{C} 2_{\mathrm{aq}}$ to form the intermediates, IMc-C $1_{\mathrm{aq}}$ and $\mathrm{IMc}-\mathrm{C} 2_{\mathrm{aq}}$, respectively. The $\Delta \mathrm{G}$ values for both TS are 12.0 and $10.8 \mathrm{kcal} \mathrm{mol}^{-1}$ but higher than the gas phase values. This is probably due to the fact that the ionic nucleophile is more stabilized in solvent than in gas phase. In the elimination step, the leaving group -OAr is eliminated from both intermediates having orientations through TS2c-C1 $1_{\text {aq }}$ and TS2c-C2 $2_{\text {aq }}$ to form solvolyzed products. The normal-mode analysis and the IRC calculation confirmed that both transition states are well connected between the intermediate and product structures. The afore-mentioned reaction mechanisms are in 


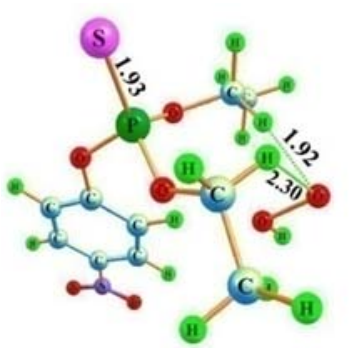

RCb

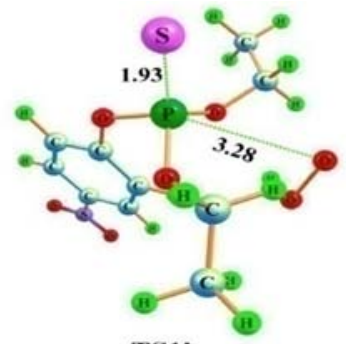

TS1b
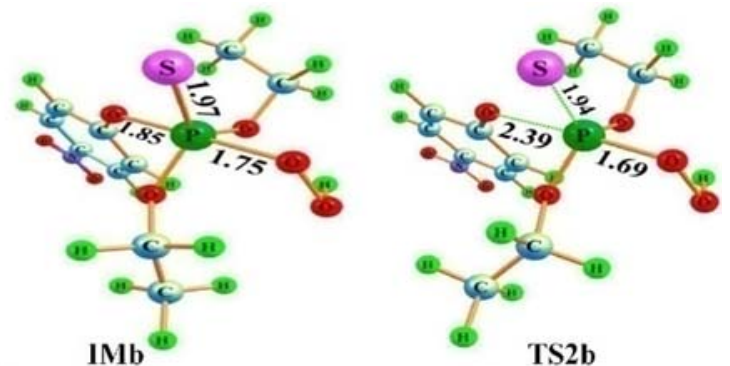

TS2b

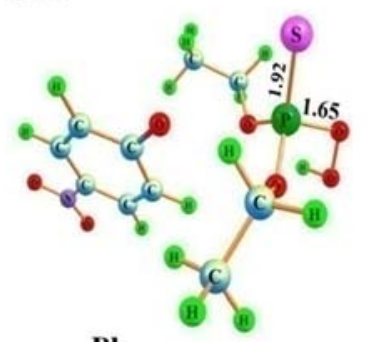

$\mathbf{P b}$

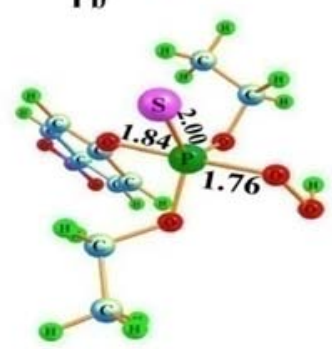

$\mathrm{IMb}_{\mathrm{C}} \mathbf{C 1}_{\mathrm{aq}}$

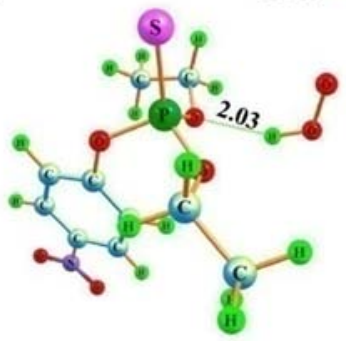

$\mathrm{RCb}-\mathrm{Cl}_{\text {aq }}$

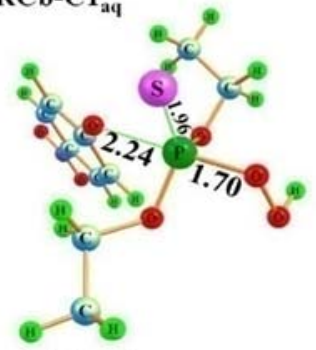

TS2b-C1 $1_{\text {aq }}$

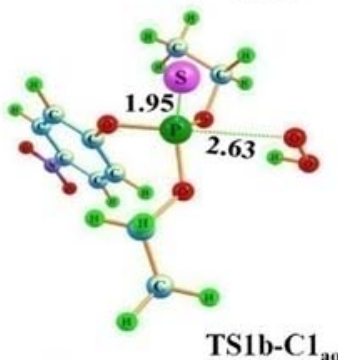

TS1b-C1

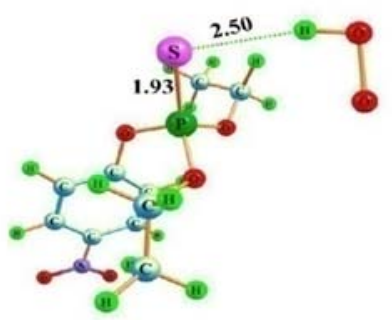

RCb-C2 aq

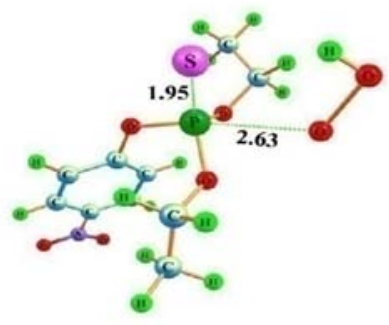

TS1b-C $2_{\text {aq }}$
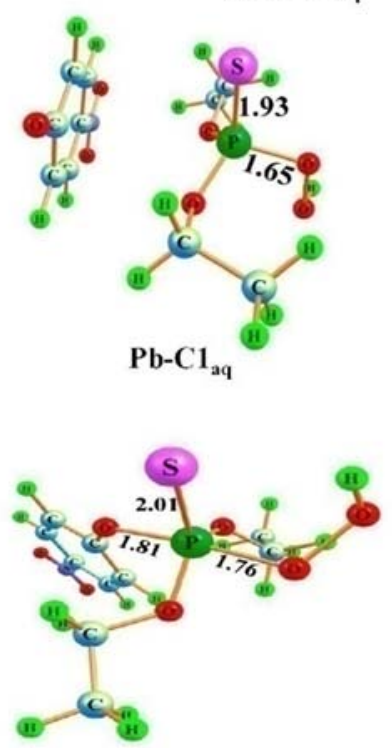

IMb-C2 $2_{\text {aq }}$

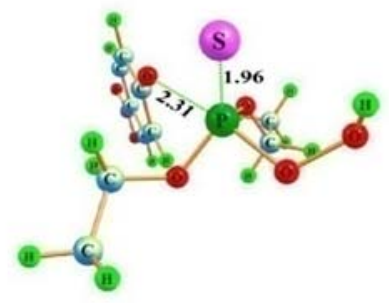

TS2b-C2 aq

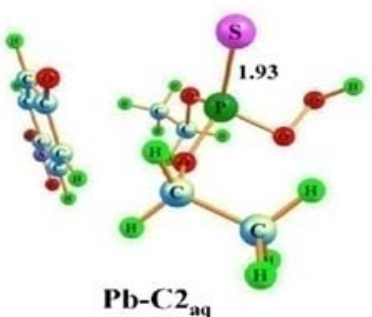

Figure 4. Optimized geometries with important parameters in the gas and aqueous phases obtained at M062X/6-31++G(d,p) level for all the species involved in the reaction of parathion with $\mathrm{HOO}^{-}$. All bond lengths are in $\AA$.

good agreement with addition-elimination mechanism in spite of the orientation of different incoming nucleophilic group. Moreover, the first step of nucleophilic

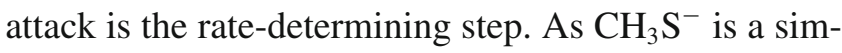
ple nucleophile, there is no possibility of any enhanced nucleophilic effect like other $\alpha$-nucleophiles. Though 


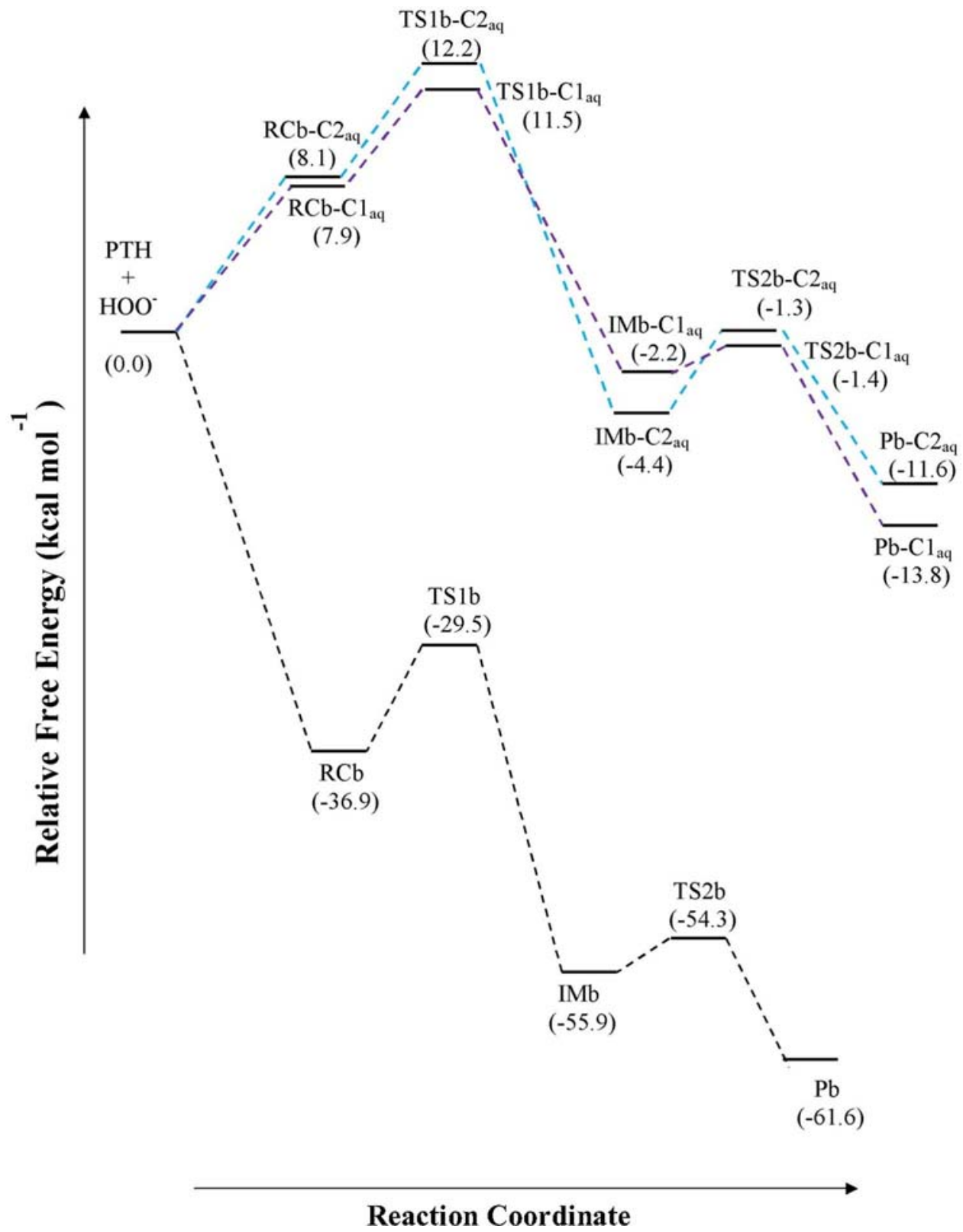

Figure 5. Free energy profile for the reaction of parathion with $\mathrm{HOO}^{-}$at M062X/6-31++G(d,p) level of theory in gas (black color line) and aqueous (violet and cyan color lines) phases. C1 (violet line) and C2 (cyan line) correspond to the relative orientation in aqueous phase.

$\mathrm{CH}_{3} \mathrm{~S}^{-}$is a simple nucleophile, it also shows multistep addition-elimination pathways.

\subsection{Reactivity trend of three nucleophiles}

We now discuss about the nucleophilic reactivity based energetic and conceptual parameters values. Nucleophilicity can be correlated by comparing the rate determining transition state structure for different nucleophiles. It is clear from Table 1 that the first transition state of nucleophilic attack is the rate determining state in both gas and aqueous phases. The calculated $\Delta \mathrm{G}$ value for TS1c is $0.4 \mathrm{kcal} \mathrm{mol}^{-1}$ lower compared to the corresponding transition state TS1b and $0.2 \mathrm{kcal} \mathrm{mol}^{-1}$ higher than the TS1a in gas phase. But from these relative energetic values $(\Delta \mathrm{G})$, the trend in reactivity cannot be predicted in gas phase. In case of aqueous phase, $\Delta \mathrm{G}$ is similar for TS1a-C $1_{\mathrm{aq}}$ and $\mathrm{TS} 1 \mathrm{~b}-\mathrm{C} 1_{\mathrm{aq}}$ but both are lower in $\Delta \mathrm{G}$ than $\mathrm{TS} 1 \mathrm{c}-\mathrm{Cl}_{\mathrm{aq}}$. The order of reactivity for nucleophilic attack for $\mathrm{C}_{1 \mathrm{aq}}$ can be predicted from the aqueous phase energetics data and it is $\mathrm{NH}_{2} \mathrm{O}^{-} \approx \mathrm{HOO}^{-}>\mathrm{CH}_{3} \mathrm{~S}^{-}$, whereas in case of $\mathrm{C}_{\mathrm{aq}}$ 


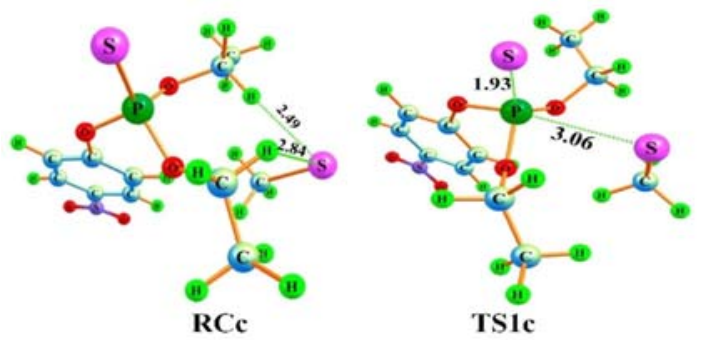

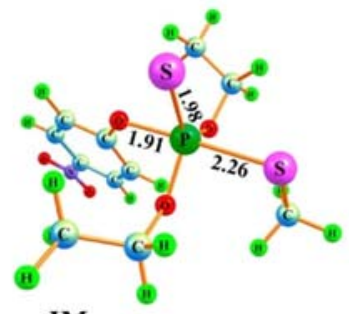

IMc

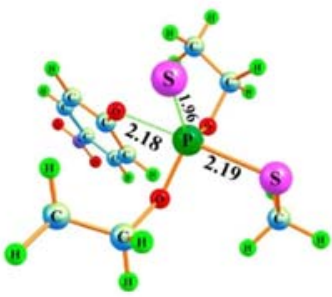

TS2c

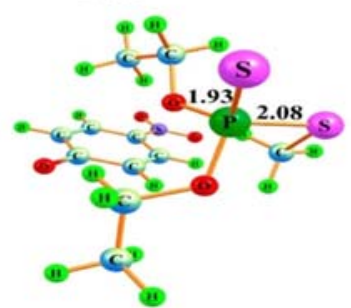

Pc

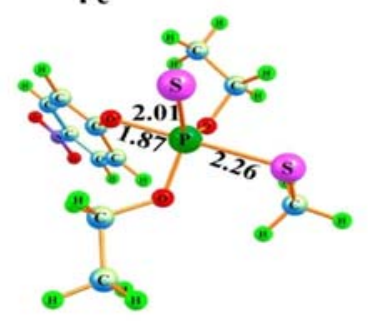

IMc-C $1_{\text {ay }}$
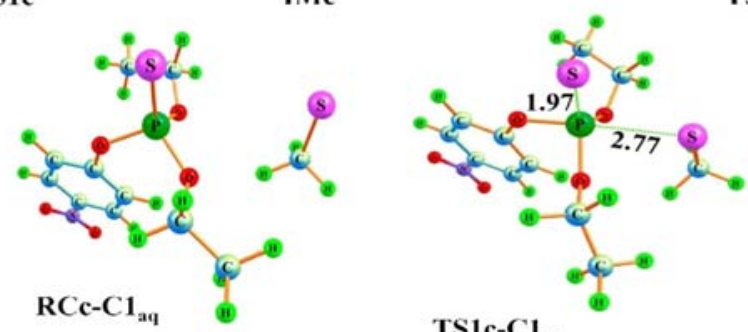

TS1c-C1 aq

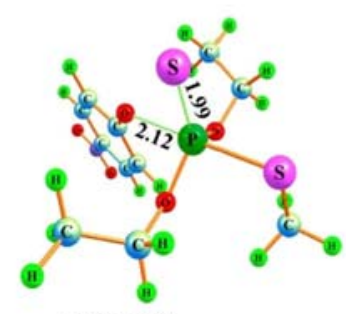

$\mathrm{TS} 2 \mathrm{c}-\mathrm{C} 1_{\text {aq }}$
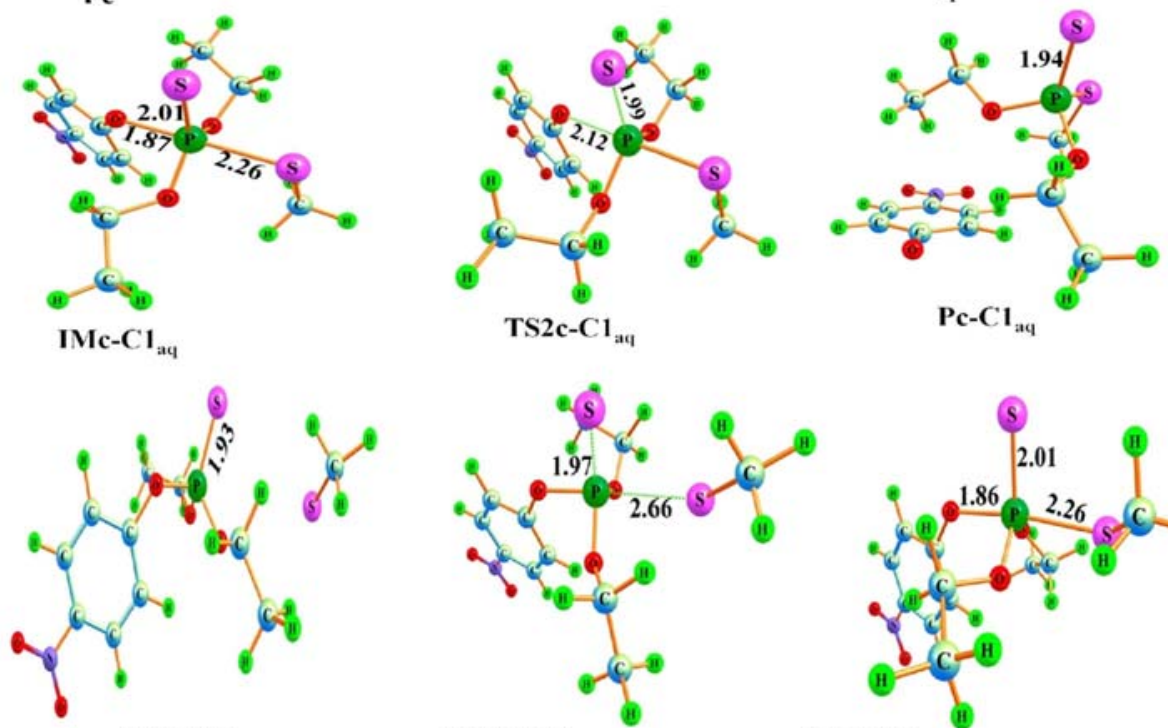

$\mathrm{RCc}-\mathrm{C} 2_{\text {aq }}$
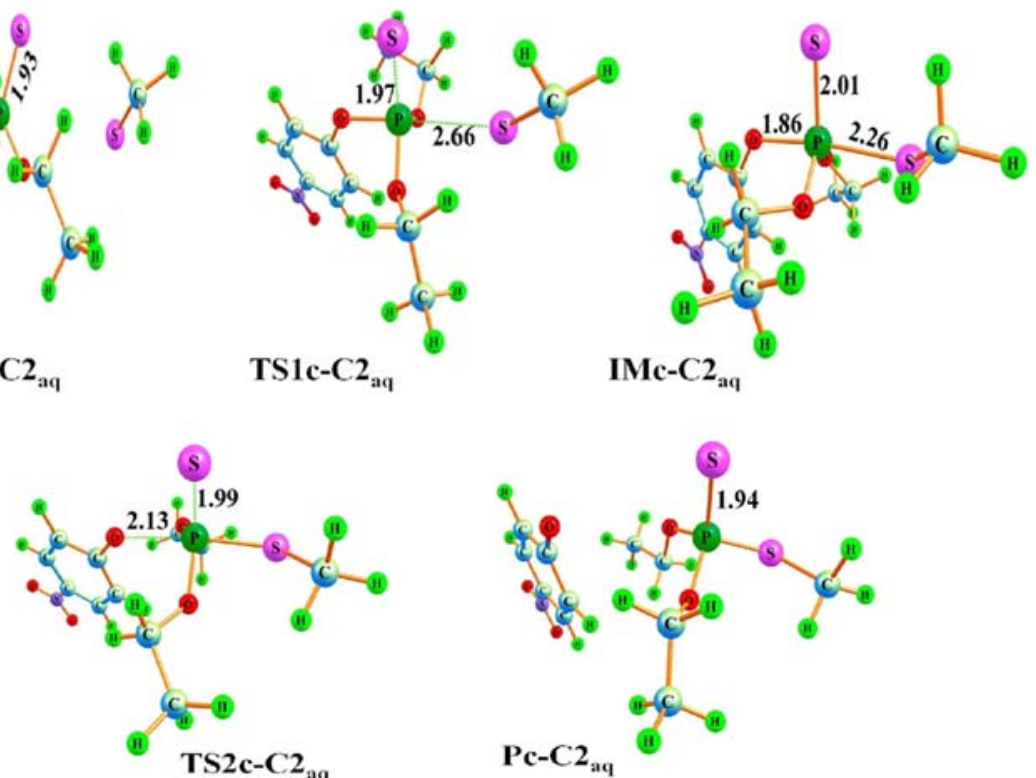

Figure 6. Optimized geometries with important parameters in the gas and aqueous phases obtained at M062X/6-31++G(d,p) level for all the species involved in the reaction of parathion with $\mathrm{CH}_{3} \mathrm{~S}^{-}$. All bond lengths are in $\AA$.

pathway, $\Delta \mathrm{G}$ value for $\mathrm{TS} 1 \mathrm{~b}-\mathrm{C} 2_{\mathrm{aq}}$ is lower than that of TS1a-C2 $2_{\mathrm{aq}}$ and $\mathrm{TS} 1 \mathrm{c}-\mathrm{C} 2_{\mathrm{aq}}$. Hence, reactivity trend should be $\mathrm{HOO}^{-}>\mathrm{NH}_{2} \mathrm{O}^{-}>\mathrm{CH}_{3} \mathrm{~S}^{-}$. So, the reactivity trend is different in aqueous phase and it may be concluded that there is significant enhancement of $\alpha$ effect for $\alpha$-nucleophiles in aqueous medium compared to simple nucleophiles. But the reasonable values of $\Delta \mathrm{E}$,
$\Delta \mathrm{H}$ and $\Delta \mathrm{G}$ suggest that the proposed mechanism for the solvolysis of PTH in both phases is realistic.

Conceptual DFT analysis (by means of electron density as the fundamental property) has been performed to find the trend of reactivity of $\alpha$-nucleophiles and simple nucleophiles with PTH in both phases and try to correlate it with the reactivity trend obtained from $\Delta H$ and 


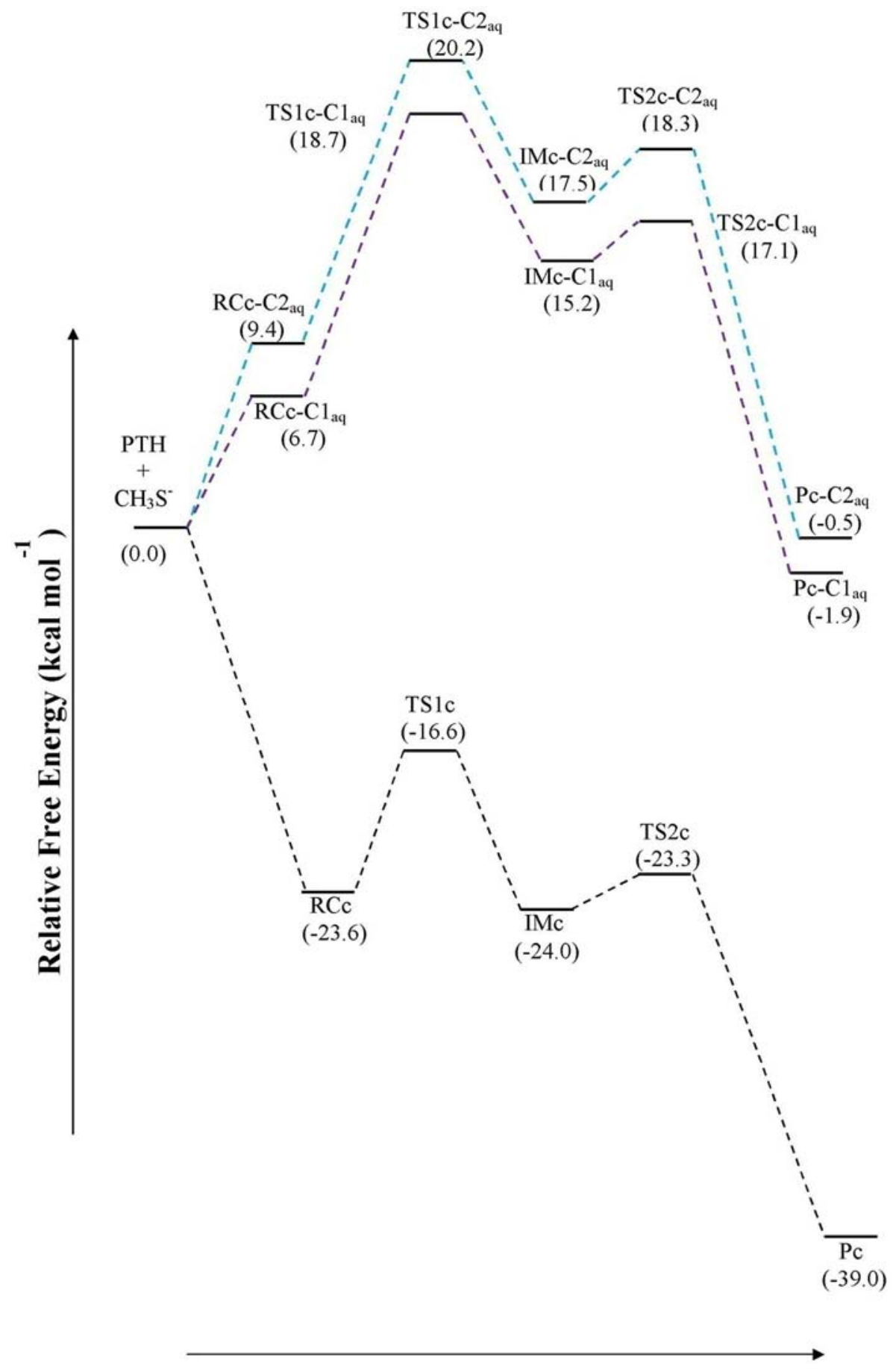

\section{Reaction Coordinate}

Figure 7. Free energy profile for the reaction of parathion with $\mathrm{CH}_{3} \mathrm{~S}^{-}$at M062X/6-31++G(d,p) level of theory in gas (black color line) and aqueous (violet and cyan color lines) phases. C1 (violet line) and C2 (cyan line) correspond to the relative orientation in aqueous phase.

$\Delta \mathrm{G}$ values. The computational procedure to calculate these values has already been described in the Computational Details section. The calculated values for Fukui function (f) and local softness parameters $\left(\mathrm{s}^{+}\right.$and $\left.\mathrm{s}^{-}\right)$, the differences $(\Delta s)$ of $\mathrm{s}^{+}$and $\mathrm{s}^{-}$are presented in Table 2 .
In the gas phase, the increasing order of $\Delta s$ values is as follows: $\mathrm{HOO}^{-}<\mathrm{NH}_{2} \mathrm{O}^{-}<\mathrm{CH}_{3} \mathrm{~S}^{-}$. Therefore, the conceptual DFT results clearly infer that the reactivity of $\mathrm{HOO}^{-}$is greater than that of $\mathrm{NH}_{2} \mathrm{O}^{-}$and $\mathrm{CH}_{3} \mathrm{~S}^{-}$for the SN2@P attack on PTH, based on addition-elimination 
Table 2. Global Softness (S), Local Softness $\left(\mathrm{s}^{+}\right.$and $\left.\mathrm{s}^{-}\right)$and Fukui Function (f) for the $\alpha$-nucleophiles $\left(\mathrm{NH}_{2} \mathrm{O}^{-}, \mathrm{HOO}^{-}, \mathrm{CH}_{3} \mathrm{~S}^{-}\right)$and Parathion, reactivity (difference in Local Softness $(\Delta s)$ between parathion and $\alpha$-Nucleophile) are calculated using Mulliken charge at M062X/6-31++G(d,p) level in the gas as well as in aqueous phase (in parentheses).

\begin{tabular}{lcrrr}
\hline Species & $\mathrm{S}$ & $\mathrm{F}$ & $\mathrm{s}+$ and $\mathrm{s}-$ & $\Delta \mathrm{s}$ \\
\hline $\mathrm{NH}_{2} \mathrm{O}^{-}$ & $7.726(4.206)$ & $-0.567(-0.565)$ & $-4.381(-2.377)$ & $5.690(2.301)$ \\
$\mathrm{HOO}^{-}$ & $6.072(3.722)$ & $-0.643(-0.657)$ & $-3.904(-2.448)$ & $5.213(2.372)$ \\
$\mathrm{CH}_{3} \mathrm{~S}^{-}$ & $6.628(4.141)$ & $-0.879(-0.928)$ & $-5.826(-3.843)$ & $7.135(3.767)$ \\
$\mathrm{PTH}$ & $3.945(4.057)$ & $0.332(-0.018)$ & $1.309(-0.075)$ & \\
\hline
\end{tabular}

mechanism. However, the increasing order of $\Delta \mathrm{s}$ values in aqueous phase is as follows: $\mathrm{NH}_{2} \mathrm{O}^{-}<\mathrm{HOO}^{-}<$ $\mathrm{CH}_{3} \mathrm{~S}^{-}$and it indicates that the reactivity of $\mathrm{NH}_{2} \mathrm{O}^{-}$is greater than that of $\mathrm{HOO}^{-}$and $\mathrm{CH}_{3} \mathrm{~S}^{-}$for the SN2@P attack on PTH. In addition, the computational analyses performed for the solvolysis of PTH suggest that the overall process seems to be a delicate balance between nucleophilicity and stabilization of intermediates and transition state. It may be concluded that other than the nucleophilicity of nucleophiles, reaction medium as well as electronic and structural factors could also be important to govern the rate of solvolysis of PTH. So, the reactivity trends for simple as well as $\alpha$-nucleophiles for the SN2@P reactions with PTH through additionelimination mechanism have been established.

\section{Conclusions}

The gas and aqueous phase reactions of the $\alpha$-nucleophiles $\left(\mathrm{NH}_{2} \mathrm{O}^{-}, \mathrm{HOO}^{-}\right)$and simple nucleophile $\left(\mathrm{CH}_{3} \mathrm{~S}^{-}\right)$ with neutral PTH have been studied in detail, theoretically. Mechanistic studies bestow light on the solvolysis reactions of PTH, based on multistep additionelimination pathways which pass through the trigonal bipyramidal intermediates at phosphorus center. The reaction mechanism is independent of the relative orientation of the attacking nucleophile. The rate-determining step of multistep mechanisms appears to be associated with formation of an intermediate. The free energy barrier is lower for $\alpha$-nucleophiles in aqueous phase compared to gas phase, indicating that the $\alpha$-effect is significant in presence of solvent; but the results obtained for simple nucleophile is reverse. It is probably due to the stabilization of ionic nucleophiles by solvent. There is no significant $\alpha$-effect in gas phase reactions for $\alpha$-nucleophiles compared to simple nucleophiles. Moreover, the conceptual DFT analysis shows that the order of reactivity for all nucleophiles is different in aqueous phase compared to gas phase. After summarizing the results, it is worth mentioning that the order of reactivity of nucleophiles based on forward activation energy barriers contradicts the conceptual DFT results in gas phase but it corroborates well in aqueous phase. Therefore, the most plausible explanation for the above fact is that the nucleophilicity and ability of leaving-group are important to determine the efficiency of nucleophilic reaction and it can be influenced by the medium of the nucleophilic reaction, electronegativity, stabilization of the transition states, intermediates, etc. In addition, these results are supported well by the previous ${ }^{93}$ findings, which reported that the assessment of $\alpha$-effect by conventional way can be ambiguous due to some controversial results obtained for gas phase reaction for the chosen $\alpha$-nucleophiles compared to simple nucleophiles. We hope this work will serve as a reference for investigating the intrinsic reactivity of these types of compounds and can provide some useful information for further experimental and theoretical studies.

\section{Supplementary Information (SI)}

Relative energies, Cartesian coordinates of all optimized geometries are given in the Supplementary Information., which is available at www.ias.ac.in/chemsci.

\section{Acknowledgements}

CS is grateful to the Council of Scientific and Industrial Research (CSIR), Government of India, for providing him research fellowships. AKD is grateful to the Department of Science and Technology (DST), Govt. of India, for a research grant under scheme number: SB/S1/PC-79/2012.

\section{References}

1. Donaldson D, Kiely T and Grube A 2002 In Pesticide Industry Sales, Usage: (1998, 1999). Market Estimates EPA-733-R-02-001 (Washington, DC: United States Environmental Protection Agency)

2. (a) Eyer P, Szinicz L, Thiermann H, Worek F and Zilker T 2007 Testing of antidotes for organophosphorus compounds: experimental procedures and clinical reality 
Toxicology 233 108; (b) Petroianu G A, Arafat K, Nurulain S M, Kuca K and Kassa J 2007 In vitro oxime reactivation of red blood cell acetylcholinesterase inhibited by methyl-paraoxon J. Appl. Toxicol. 27 168; (c) Briseno-Roa L, Hill J, Notman S, Sellers D, Smith A P, Timperley C M, Wetherell J, Williams N H, Williams G R, Fersht A R and Griffiths A D 2006 Analogues with fluorescent leaving groups for screening and selection of enzymes that efficiently hydrolyze organophosphorus nerve agents J. Med. Chem. 49 246; (d) Yu S J 2006 Insensitivity of acetylcholinesterase in a field strain of the fall armyworm Spodoptera frugiperda (J.E. Smith) Pestic. Biochem. Phys. 84 135; (e) Silva Filho M V, Oliveira M M, Salles J B, Bastos V L F C, Cassano V P F and Bastos J C 2006 Methyl-paraoxon comparative inhibition kinetics for acetylcholinesterases from brain of neotropical fishes Toxicol. Lett. 153 247; (f) Jackson C J, Liu J -W, Coote M L and Ollis D L 2005 The effects of substrate orientation on the mechanism of a phosphotriesterase Org. Biomol. Chem. 3 4343; (g) Wan H B, Wong M K and Mok C Y 1994 Mercury (II) ion-promoted hydrolysis of some organophosphorus pesticides Pestic. Sci. 4293

3. (a) Mishra S, Reddy-Noone K, Jain A and Verma K K 2006 Monitoring organophosphorus pesticides and their degradation products formed by Fenton's reagent using solid-phase extraction gas chromatography mass spectrometry Int. J. Environ. Pollut. 27 49; (b) Duquesne S, Reynaldi S and Liess M 2006 Effects of the organophosphate paraoxon-methyl on survival and reproduction of Daphnia magna: importance of exposure duration and recovery Environ. Toxicol. Chem. 25 1196; (c) Lartiges S B and Garrigues P P 1995 Degradation Kinetics of Organophosphorus and Organonitrogen Pesticides in Different Waters under Various Environmental Conditions Environ. Sci. Technol. 29 1246; (d) Lacorte S and Barceló D 1994 Rapid Degradation of Fenitrothion in Estuarine Waters Environ. Sci. Technol. 28 1159

4. Wu T, Gan Q and Jans U 2006 Nucleophilic Substitution of Phosphorothionate Ester Pesticides with Bisulfide $\left(\mathrm{HS}^{-}\right)$and Polysulfides $\left(\mathrm{S}_{n}^{2-}\right)$ Environ. Sci. Technol. 40 5428

5. Chanda A, Khetan S K, Banerjee D, Ghosh A and Collins T J 2006 Total Degradation of Fenitrothion and Other Organophosphorus Pesticides by Catalytic Oxidation Employing Fe-TAML Peroxide Activators J. Am. Chem. Soc. 12812058

6. Liu B, McConnell L L and Torrents A 2001 Hydrolysis of chlorpyrifos in natural waters of the Chesapeake Bay Chemosphere 441315

7. Bravcon Kralj M, Cernigoj U, Franko M and Trebse P 2007 Comparison of photocatalysis and photolysis of malathion, isomalathion, malaoxon, and commercial malathion-products and toxicity studies Water Res. 41 4504

8. Bravcon Kralj M, Franko M and Trebse P 2007 Photodegradation of organophosphorus insecticides Investigations of products and their toxicity using gas chromatography-mass spectrometry and AChEthermal lens spectrometric bioassay Chemosphere 6799
9. Wanner O, Egli T, Fleischmann T, Lanz K, Reichert P and Schwarzenbach R P 1989 Behavior of the insecticides disulfoton and thiometon in the Rhine River: A chemodynamic study Environ. Sci. Technol. 231232

10. Han X, Balakrishnan V K, vanLoon G W and Buncel E Degradation of the Pesticide Fenitrothion as Mediated by Cationic Surfactants and $\alpha$-Nucleophilic Reagents 2006 Langmuir 229009

11. Omakor J E, Onyido I, vanLoon G W and Buncel E 2001 Competing pathways in the reaction of the pesticide Fenitrothion [O,O-dimethyl O-(3-methyl4-nitro-phenyl) phosphorothioate] with some nitrogen nucleophiles in aqueous solution J. Chem. Soc. Perkin Trans. 2324

12. (a) Pignatello J J and Sun Y F 1995 Complete oxidation of metolachlor and methyl parathion in water by the photoassisted fenton reaction Water Res. 29 1837; (b) Menger F M and Rourk M J 1999 Deactivation of Mustard and Nerve Agent Models via Low-Temperature Microemulsions Langmuir 15309

13. Rougier N M, Vico R V, Rossi R H D and Bujan E I 2010 Reactivity of the Insecticide Fenitrothion toward $\mathrm{O}$ and N Nucleophiles J. Org. Chem. 753427

14. Kesharwani M K, Khan M A S, Bandyopadhyay T and Ganguly B 2010 Solvolysis process of organophosphorus compound $P$-[2-(dimethylamino)ethyl]- $N, N$ dimethylphosphonamidic fluoride with simple and $\alpha$ nucleophiles: A DFT study Theor. Chem. Acc. 12739

15. Mandal D, Mondal B and Das A K 2010 Isomerization and Decomposition of a Model Nerve Agent: A Computational Analysis of the Reaction Energetics and Kinetics of Dimethyl Ethylphosphonate J. Phys. Chem. A 114 10717

16. Dyguda-Kazimierowicz E, Sokalski W A and Leszczynski J 2008 Gas-Phase Mechanisms of Degradation of Hazardous Organophosphorus Compounds: Do They Follow a Common Pattern of Alkaline Hydrolysis Reaction As in Phosphotriesterase? J. Phys. Chem. B 112 9982

17. Xiong Y and Zhan C G 2004 Reaction pathways and free energy barriers for alkaline hydrolysis of insecticide 2trimethylammonioethyl methylphosphonofluoridate and related organophosphorus compounds: Electrostatic and steric effects J. Org. Chem. 698451

18. Patterson E V and Cramer C G 1998 Molecular orbital calculations on the $\mathrm{P}-\mathrm{S}$ bond cleavage step in the hydroperoxidolysis of nerve agent VX J. Phys. Org. Chem. 11232

19. Mandal D, Mondal B and Das A K 2012 Nucleophilic degradation of fenitrothion insecticide and performance of nucleophiles: A computational study J. Phys. Chem. A 1162536

20. Iglesias E 2001 Ethyl Cyclohexanone-2-carboxylate in Aqueous Micellar Solutions. 1. Ester Hydrolysis in Cationic and Nonionic Micelles J. Phys. Chem. B 105 10287; (b) Ghosh K K, Tiwari S, Marek J and Kuca K 2010 Cationic Micellar-Catalyzed Hydrolysis of Pesticide Fenitrothion Using $\alpha$-Nucleophiles Lett. Drug Des. Discovery 7194

21. (a) Toullec J and Moukawim M 1996 Cetyltrimethylammonium hydroperoxide: an efficient reagent for promoting phosphate ester hydrolysis Chem. Commun. 221; 
(b) Moss R A, Kotchevar A T, Park B D and Scrimin P 1996 Comparative Reactivities of Phosphotriesters toward Iodosocarboxylates in Cationic Micelles Langmuir 122200

22. (a) Limb J K, Jeon S E, Lee S E and Um I H 2002 Bull. Korean Chem. Soc. 1263; (b) Um I H 1990 Bull. Korean Chem. Soc. 11173

23. Domingos J B, Longhinotti E, Brao T A S, Santos L S, Eberlin M N, Bunton C A and Nome F 2004 Reaction of Bis(2,4-dinitrophenyl) Phosphate with Hydrazine and Hydrogen Peroxide. Comparison of $O$ - and $N$ - Phosphorylation J. Org. Chem. 697898

24. Fendler J H and Fendler E J 1975 In Catalysis in Micellar, Macromolecular Systems (New York: Academic Press)

25. Tarkka R M and Buncel E 1995 Origin of the bell-shaped .alpha.-effect-solvent composition plots. pKa-solvent dependence of the .alpha.-effect at a phosphorus center J. Am. Chem. Soc. 1171503

26. Kirby A J, Davies J E, Bräo T A S, da Silva P F, Rocha W R and Nome F 2006 Hydroxylamine as an oxygen nucleophile. Structure and reactivity of ammonia oxide J. Am. Chem. Soc. 12812374

27. Reviews: (a) Buncel E, Um I H and Terrier F 2009 In The Chemistry of Hydroxylamines, Oximes, Hydroxamic Acid (West Sussex: Wiley Press) Ch. 17; (b) Buncel E and Um I H 2004 Tetrahedron 60 7801; (c) Hoz S and Buncel E 1985 Isr. J. Chem. 26 313; (d) Grekov A P and Beselov V Ya 1978 Russ.Chem. Rev. 47 631; (e) Fina N J and Edwards J O 1973 Int. J. Chem. Kinet. 51

28. (a) Villano S M, Eyet N, Lineberger W C and Bierbaum V M 2009 Reactions of $\alpha$-Effect J. Am. Chem. Soc. 131 8227; (b) Depuy C H, Della E W, Filley J, Grabowski J J and Bierbaum V M 1983 Absence of an alpha-effect in the gas-phase nucleophilic reactions of hydroperoxide ion J. Am. Chem. Soc. 105 2481; (c) Wolfe S, Mitchell D J, Schlegel H B, Minot C and Eisenstein O 1982 Tetrahedron Lett. 23615

29. McAnoy A M, Paine M R and Blanksby S 2008 Reactions of the hydroperoxide anion with dimethyl methylphosphonate in an ion trap mass spectrometer: evidence for a gas phase $\alpha$-effect J. Org. Biomol. Chem. 62316

30. Patterson E V and Fountain K R 2006 On Gas Phase $\alpha$ Effects. 1. The Gas-Phase Manifestation and Potential SET Character J. Org. Chem. 718121

31. (a) Wei X G, Sun X M, Wu W P, Ren Y, Wong N B and Li W K 2010 Enhanced Reactivity of $\mathrm{RC} \equiv \mathrm{CZ}^{-}$ Reactions Revisited Org. Lett. 8119

32. Buncel E, Chuaqui C and Wilson H 1980 Bond scission in sulfur compounds. 13. Reactivity-selectivity correlations. 3. The .alpha. effect at saturated carbon. Reactivity studies of methyl phenyl sulfates with nucleophiles $J$. Org. Chem. 453621

33. (a) Kirby A J, Davies J E, Fox D J, Hodgson D R, Goeta A E, Lima M F, Priebe J P, Santaballa J A and Nome F 2010 Ammonia oxide makes up some $20 \%$ of an aqueous solution ofhydroxylamine Chem. Commun. 1302; (b) Kirby A J, Tondo D W, Medeiros M, Souza B S, Priebe J P, Lima M.F and Nome F 2009 Efficient Intramolecular General-Acid Catalysis of the Reactions of $\alpha$ Group. $J$. Am. Chem. Soc. 1277033
34. Buncel E, Cannes C, Chatrousse A-P and Terrier F 2002 Revisiting the reactivity of oximate $\alpha$-Nucleophiles with Esters: Evidence from Solvation Effects for Substantial Decoupling of Desolvation and Bond Formation J. Am. Chem. Soc. 1248766

35. (a) Fountain K R 2005 J. Phys. Org. Chem. 18 481; (b) Fountain K R, Felkerson C J, Driskell J D and Lamp B D 2003 The $\alpha$-Phenylhydroxylamine in Dimethyl Sulfoxide with Methylarenesulfonates J. Org. Chem. 619434

36. (a) Domingos J B, Longhinotti E, Brandao T A S, Santos LS, Eberlin M N, Bunton C A and Nome F 2004 Reaction of Bis(2,4-dinitrophenyl) Phosphate with Hydrazine and Hydrogen Peroxide. Comparison of $O$ - Phosphorylation J. Org. Chem. 69 7898; (b) Bunton C A, Nome F, Quina F H and Romsted L S 1991 Ion binding and reactivity at charged aqueous interfaces Acc. Chem. Res. 24 357; (c) Bunton C A, Mhala M M, Moffatt J R 1989 Nucleophilic reactions in zwitterionic micelles of amine oxide or betaine sulfonate surfactants J. Phys. Chem. 93 854; (d) Bunton C A, Gan L H, Moffatt J R, Romsted L S and Savelli G 1981 Reactions in micelles of cetyltrimethylammonium hydroxide. Test of the pseudophase model for kinetics J. Phys. Chem. 85 4118; (e) Bunton C A and Sepulveda L 1979 Hydrophobic and coulombic interactions in the micellar binding of phenols and phenoxide ions J. Phys. Chem. 83680

37. (a) Gregory M and Bruice T C 1967 alpha Effect II. Displacements on sp3 carbon J. Am. Chem. Soc. 89 4400; (b) Dixon J E and Bruice T C 1972 Alpha Effect V. Kinetic and thermodynamic nature of the alpha effect for amine nucleophiles J. Am. Chem. Soc. 94 2052; (c) Dixon J E and Bruice T C 1971 alpha Effect IV. Additional observation on the alpha effect employing malachite green as substrate J. Am. Chem. Soc. 936592

38. (a) Jencks W P 1969 In Catalysis in Chemistry, Enzymology (New York: McGraw-Hill) pp. 107-111; (b) Herschlag D and Jencks W P 1990 Nucleophiles of high reactivity in phosphoryl transfer reactions: alpha -effect compounds and fluoride ion J. Am. Chem. Soc. 112 1951; (c) Jencks W P 1985 A primer for the Bema Hapothle. An empirical approach to the characterization of changing transition-state structures Chem. Rev. 85 511; (d) Jencks W P and Gilchrist M 1968 Nonlinear structure-reactivity correlations. The reactivity of nucleophilic reagents toward esters J. Am. Chem. Soc. 902622 ; (e) Jencks W P 1958 The Reaction of Hydroxylamine with Activated Acyl Groups II. Mechanism of the Reaction J. Am. Chem. Soc. 804585

39. (a) Bernasconi C F, Leyes A E, Eventova I and Rappoport Z 1995 Kinetics of the Reactions of beta Methoxy- alpha -nitrostilbene with Methoxyamine and N-Methylmethoxyamine. Direct Observation of the Intermediate in Nucleophilic Vinylic Substitution J. Am. Chem. Soc. 117 1703; (b) Bernasconi C F 1992 The Principle of Non-perfect Synchronization Adv. Phys.Org. Chem. 27 119; (c) Bernasconi C F and Stronach M W 1991 Kinetics of amine addition to benzylidenemalonodialdehyde in $50 \%$ dimethyl sulfoxide - 50\% water J. Org. Chem. 56 1993; (d) Bernasconi C F 1987 Intrinsic barriers of reactions and the principle of nonperfect synchronization Acc. Chem. Res. 20 301; (e) 
Bernasconi C F and Murray C J 1986 Nucleophilic addition to olefins. 18. Kinetics of the addition of primary amines and alpha -effect nucleophiles to benzylidene Meldrum's acid J. Am. Chem. Soc. 1085251

40. (a) Hoz S and Buncel E 1984 Pitfalls in the determination of the $\alpha$-effect? Tetrahedron Lett. 24 4777; (c) Hoz S 1982 The alpha effect: on the origin of transition-state stabilization J. Org. Chem. 473545

41. (a) Ghosh K K, Tiwari S, Marek J and Kuca K 2010 Spectrophotometric Determination of the Acidity Constants of Some Oxime-Based $\alpha$-methyl 4-methoxy benzohydroxamate ion J. Mol. Liq. 14199

42. (a) Um I H, Han J Y and Buncel E 2009 Effects on the Reactivity by Changing the Electrophilic Center from $\mathrm{C}=\mathrm{O}$ to $\mathrm{C}=\mathrm{S}$ : Contrasting Reactivity of Hydroxide, $p$ Effect:? Dissection of Ground-State and Transition-State Contributions J. Org. Chem. 65577

43. (a) Um I H, Shin Y H, Han J Y and Buncel E 2006Medium effects on the $\alpha$-Effect as Expressed by Solvent EffectsJ. Am. Chem. Soc. 12311111

44. (a) Um I H, Han H J, Ahn J A, Kang S and Buncel E 2002 Reinterpretation of Curved Hammett Plots in Reaction of Nucleophiles with Aryl Benzoates: Change in RateDetermining Step or Mechanism versus Ground-State Stabilization J. Org.Chem. 67 8475; (b) Um I H, Lee E J and Buncel E 2001Solvent Effect on the $\alpha$ solvent system Chem. Commun. 1917

45. Thomsen D L, Nichols C M, Reece J N, Hammerum S and Bierbaum V M 2014 The $\alpha$-effect and competing mechanisms: The gas phase raction of microsolvated anions with methyl formate J. Am. Soc. Mass Spectrom. 25159

46. Garver J M, Gronert S and Bierbaum V M 2011 Experimental Validation of the $\alpha$-Effect in the Gas Phase J. Am. Chem. Soc. 13313894

47. Kamps J A G, Belle R and Mecinovic 2013Hydroxylamine as an oxygen nucleophile: substitution of sulfonamide by a hydroxyl group in benzothiazole-2sulfonamides Org. Biomol. Chem. 111103

48. (a) Um I H, Kim E H and Lee J Y 2009 Kinetic Studies on Nucleophilic Substitution Reactions of $O$-Aryl Thionobenzoates: Amine Basicity Combines with Modulation of the Nature of Substituents in the Leaving Group and Thionobenzoate Moiety to Control the Reaction Mechanism J. Org. Chem. 737671

49. Afzal D and Fountain K R 2011 Exploration of the $\alpha$ effect by substitution on hydroxylamine anions I. Effects of alkyl- and fluoroalkylation Can. J. Chem. 891343

50. Liang J X, Geng Z Y and Wang Y C 2012 Density functional study of $\mathrm{S}_{\mathrm{N}} 2$ substitution reactions for $\mathrm{CH}_{3} \mathrm{Cl}+\mathrm{CX}^{1} \mathrm{X}^{2-}\left(\mathrm{X}^{1} \mathrm{X}^{2}=\mathrm{HH}, \mathrm{HF}, \mathrm{HCl}, \mathrm{HBr}, \mathrm{HI}, \mathrm{FF}\right.$, $\mathrm{ClCl}, \mathrm{BrBr}$, andII) J. Comput. Chem. 33595

51. (a) Song Y and Cooks R G 2007 Reactive desorption electrospray ionization for selective detection of the hydrolysis products of phosphonate esters J. Mass Spectrom . 42 1086; (b) Faye T, Mathurin J C, Brunot A, Tabet J C, Walls G and Fuche C 2000 High-Pressure Ion Source Combined with an In-Axis Ion Trap Mass Spectrometer 2. Application of Selective Low-Pressure Negative Ion Chemical Ionization Anal. Chem. 72 5063; (c) Steiner V, Daoust-Maleval I and Tabet J C 2000 Formation and structural discrimination of stable halophenylium ions in the gas phase1 Int. J. Mass Spectrom. 195-196 121; (d) Lum R C and Grabowski J J 1992 Trimethyl phosphate: the intrinsic reactivity of carbon versus phosphorus sites with anionic nucleophiles J. Am. Chem. Soc. 114 8619; (e) Hodges R V, McDonnell T J, Beauchamp J L 1980 Properties and reactions of trimethyl phosphite, trimethyl phosphate, triethyl phosphate, and trimethyl phosphorothionate by ion cyclotron resonance spectroscopy $J$. Am. Chem. Soc. 102 1327; (f) Hodges R V, Sullivan S A and Beauchamp J L 1980 Nucleophilic reactions of anions with trimethyl phosphate in the gas phase by ion cyclotron resonance spectroscopy J. Am. Chem. Soc. 102 935

52. Lum R C and Grabowski J J 1993Carbon versus phosphorus site selectivity in the gas-phase anion-molecule reactions of dimethyl methylphosphonate J. Am. Chem. Soc. 1157823

53. McAnoy A M, Williams J, Paine M R L, Rogers M L and Blanksby S J 2009 Ion-molecule reactions of O, S-dimethyl methylphosphonothioate: evidence for intramolecular sulfur oxidation during VX perhydrolysis J. Org. Chem. 749319

54. (a) Ghosh K K, Sinha D, Satnami M L, Dubey D K, Shrivastava A, Palepu R M and Dafonte P R 2006 Enhanced nucleophilic reactivity of hydroxamate ions in some novel micellar systems for the cleavage of Parathion $J$. Colloid Interface Sci. 301 564; (b) Um I H, Jeon S E, Baek M H and Park H R 2003 Significant and differential acceleration of dephosphorylation of the insecticides, paraoxon and parathion, caused by alkali metal ethoxides Chem. Commun. 3016; (c) Han X M, Balakrishnan V K and Buncel E 2007 Alkaline Degradation of the Organophosphorus Pesticide Fenitrothion as Mediated by Cationic $\mathrm{C}_{12}$ Surfactants Langmuir 23 6519; (d) Castro E A, Ugarte D, Rojas M F, Pavez P and Santos J G 2011 Nucleophilic substitution reactions of diethyl 4nitrophenyl phosphate triester: Kinetics and mechanism Int. J. Chem. Kinet. 43708

55. Seckute J, Menke J L, Emnett R J, Patterson E V and Cramer C J 2005 Ab Initio Molecular Orbital and Density Functional Studies on the Solvolysis of Sarin and $O, S$-Dimethyl Methylphosphonothiolate, a VXlike Compound J. Org. Chem. 708649

56. Kumar P V, Ganguly B and Bhattacharya S 2004 Computational Study on Hydroxybenzotriazoles as Reagents for Ester Hydrolysis J. Org. Chem. 698634

57. Daniel K A, Kopff L A and Patterson E V, 2008 Computational studies on the solvolysis of the chemical warfare agent VX J. Phys. Org. Chem. 21321

58. Xia F, Tian K and Zhu H 2013Density functional calculations on alcoholysis and thiolysis of phosphate triesters: Stepwise or concerted? Comput. Theor. Chem. 101760

59. Xia F and Zhu H 2012 Effect of sulfur substitution

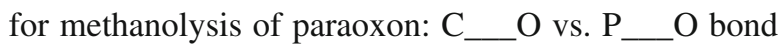
cleavage from density-functional theory Comput. Theor. Chem. 9828

60. Arantes G M and Chaimovich H 2005 Thiolysis and Alcoholysis of Phosphate Tri- and Monoesters with Alkyl and Aryl Leaving Groups. An ab Initio Study in the Gas Phase J. Phys. Chem. A 1095625

61. Allouche A R Gabedit. http://gabedit.sourceforge.net/ (Access date: July 2015) 
62. Stewart J J P, MOPAC(2009) Stewart Computational Chemistry, version 9.259W. http://openmopac. net/ (Access date: July 2015)

63. Zhao Y and Truhlar D G 2008 The M06 suite of density functionals for main group thermochemistry, thermochemical kinetics, noncovalent interactions, excited states, and transition elements: two new functionals and systematic testing of four M06-class functionals and 12 other functionals Theor. Chem. Acc. 120215

64. Hehre W J, Ditchfield R and Pople J A 1972 A Self consistent molecular orbital methods XX. A basis set for correlated wave functions J. Chem. Phys. 562257

65. Gonzales C and Schlegel H B 1989 An improved algorithm for reaction path following J. Chem. Phys. 902154

66. Gonzales C and Schlegel H B 1990 Reaction path following in mass-weighted internal coordinates J. Phys. Chem. 945523

67. Møller C and Plesset M S 1934 Note on an Approximation Treatment for Many-Electron Systems Phys. Rev. 46 618

68. Head-Gordon M, Pople J A and Frisch M J 1988 MP2 energy evaluation by direct methods Chem. Phys. Lett. 153503

69. Frisch M J, Head-Gordon M and Pople J A 1990 A direct MP2 gradient method Chem. Phys. Lett. 166275

70. Frisch M J, Head-Gordon M, Pople J A 1990 Semi-direct algorithms for the MP2 energy and gradient Chem. Phys. Lett. 166281

71. Krishnan R, Binkley J S, Seeger R and Pople A 1980 A Self- Consistent Molecular Orbital Methods XX. A Basis Set for Correlated Wave Functions J. Chem. Phys. 72650

72. Clark T, Chandrasekhar J, Spitznagel G W and Schleyer P V R 1983 Efficient Diffuse Function-Augmented Basis-Sets for Anion Calculations III. The 3-21+G Basis Set for 1st-Row Elements, Li-F J. Comput. Chem. 4294

73. Klamt A and Schuurmann G 1993 COSMO: a new approach to dielectric screening in solvents with explicit expressions for the screening energy and its gradient $J$. Chem. Soc. Perkin Trans. 2799

74. Frisch M J, Trucks G W, Schlegel H B, Scuseria G E, Robb M A, Cheeseman J R, Scalmani G, Barone V, Mennucci B, Petersson G A, Nakatsuji H, Caricato M, Li X, Hratchian H P, Izmaylov A F, Bloino J, Zheng G, Sonnenberg J L, Hada M, Ehara M, oyota KT, Fukuda R, Hasegawa J, Ishida M, Nakajima T, Honda Y, Kitao O, Nakai H, Vreven T, Montgomery J A Jr., Peralta J E, Ogliaro F, Bearpark M, Heyd J J, Brothers E, Kudin K N, Staroverov V N, Keith T, Kobayashi R, Norm J, Raghavachari K, Rendell A, Burant J C, Iyengar S S, Tomasi J, Cossi M, Rega N, Millam J M, Klene M, Knox J E, Cross J B, Bakken V, Adamo C, Jaramillo J, Gomperts R, Stratmann R E, Yazyev O, Austin A J, Cammi R, Pomelli C, Ochterski J W, Martin R L, Morokuma K, Zakrzewski V G, Voth G A, Salvador P, Dannenberg J J, Dapprich S, Daniels A D, Farkas O, Foresman J B, Ortiz J V, Cioslowski J and Fox D J 2010 Gaussian 09, ReVision B.01 (Gaussian Inc.: Wallingford)

75. Tomasi J and Persico M 1994 Molecular Interactions in Solution: An Overview of Methods Based on Continuous Distributions of the Solvent Chem. Rev. 942027
76. Cossi M, Barone V, Cammi R and Tomasi J 1996 Ab initio study of solvated molecules: a new implementation of the polarizable continuum model Chem. Phys. Lett. 255327

77. Barone V, Cossi M and Tomasi J 1996 A new definition of cavities for the computation of solvation free energies by the polarizable continuum model J. Chem. Phys. 107 3210

78. Barone V, Cossi M and Tomasi J 1998 Geometry optimization of molecular structures in solution by the polarizable continuum model J. Comput. Chem. 19404

79. Cossi M and Barone V 1998 Analytical second derivatives of the free energy in solution by polarizable continuum models J. Chem. Phys. 1096246

80. Yang W and Parr R G 1985 Hardness, softness, and the fukui function in the electronic theory of metals and catalysis Proc. Natl. Acad. Sci. U.S.A. 826723

81. Parr R G and Yang W 1984 Density functional approach to the frontier-electron theory of chemical reactivity $J$. Am. Chem. Soc. 1064049

82. Yang W and Mortier W J 1986 The use of global and local molecular parameters for the analysis of the gas-phase basicity of amines J. Am. Chem. Soc. 108 5708

83. Mulliken R 1955 Electronic Population Analysis on LCAO-MO Molecular Wave Functions I J. Chem. Phys. 231833

84. Koopmans T A 1934 Über die Zuordnung von Wellenfunktionen und Eigenwerten zu den Einzelnen Elektronen Eines Physica 1104

85. Gazquez J L 1996 The Hard and Soft Acids and Bases Principle J. Phys. Chem. A $\mathbf{1 0 1} 4657$

86. Nguyen L T, Le T N, Proft F D, Chandra A K, Lengenaeker W, Nguyen M T and Geerlings P 1999 Mechanism of $[2+1]$ Cycloadditions of Hydrogen Isocyanide to Alkynes:? Molecular Orbital and Density Functional Theory Study J. Am. Chem. Soc. 1215992

87. Ponti A 2000 DFT-Based Regioselectivity Criteria for Cycloaddition Reactions J. Phys. Chem. A104 8843

88. Ford-Green J, Majumdar D and Leszczynski J 2006 Conformational studies on parathion Int. J. Quantum. Chem. 1062356

89. Knowles J R 1980 Enzyme-Catalyzed Phosphoryl Transfer Reactions Anпu Rev. Biochem. 49877

90. Cox J R and Ramsay O B 1964 Mechanisms of Nucleophilic Substitution in Phosphate Esters Chem. Rev. 64 317

91. Zheng F, Zhan C G and Ornstein R L 2001 Theoretical Studies ofReaction Pathways and Energy Barriers for Alkaline Hydrolysis of Phosphotriesterase Substrates Paraoxon and Related Toxic Phosphofluoridate Nerve Agents J. Chem. Soc. Perkin Trans. 22355

92. Dyguda-Kazimierowicz E, Roszak, S and Andrzej Sokalski W 2014 Alkaline Hydrolysis of Organophosphorus Pesticides: The Dependence of the Reaction Mechanism on the Incoming Group Conformation $J$. Phys. Chem. B 1187277

93. Um I H, Im L R and Buncel E 2010 Pitfalls in Assessing the $\alpha$-Effect: Reactions of Substituted Phenyl Methanesulfonates with $\mathrm{HOO}^{-}, \mathrm{OH}^{-}$, and Substituted Phenoxides in $\mathrm{H}_{2} \mathrm{O}$ J. Org. Chem. 758571 